
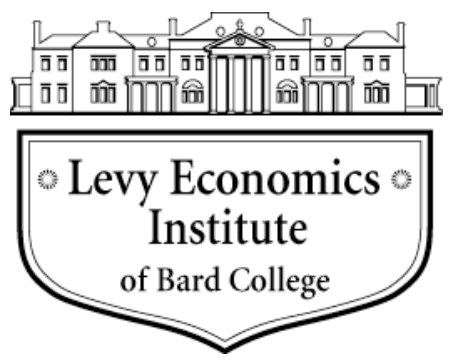

Working Paper No. 723

\title{
Fiscal Policy, Unemployment Insurance, and Financial Crises in a Model of Growth and Distribution
}

by

Greg Hannsgen*

Levy Economics Institute of Bard College

May 2012

*The author wishes to thank Amitava Dutt for advice on literature in this field and Ken Hannsgen and Marc Lavoie for helpful comments. The usual disclaimer applies. Comments are welcome. Contact:

hannsgen@levy.org.

The Levy Economics Institute Working Paper Collection presents research in progress by Levy Institute scholars and conference participants. The purpose of the series is to disseminate ideas to and elicit comments from academics and professionals.

Levy Economics Institute of Bard College, founded in 1986, is a nonprofit, nonpartisan, independently funded research organization devoted to public service. Through scholarship and economic research it generates viable, effective public policy responses to important economic problems that profoundly affect the quality of life in the United States and abroad.

Levy Economics Institute

P.O. Box 5000

Annandale-on-Hudson, NY 12504-5000

http://www.levyinstitute.org

Copyright (C) Levy Economics Institute 2012 All rights reserved 


\begin{abstract}
Recently, some have wondered whether a fiscal stimulus plan could reduce the government's budget deficit. Many also worry that fiscal austerity plans will only bring higher deficits. Issues of this kind involve endogenous changes in tax revenues that occur when output, real wages, and other variables are affected by changes in policy. Few would disagree that various paradoxes of austerity or stimulus might be relevant, but such issues can be clarified a great deal with the help of a complete heterodox model.

In light of recent world events, this paper seeks to improve our understanding of the dynamics of fiscal policy and financial crises within the context of two-dimensional (2D) and fivedimensional heterodox models. The nonlinear version of the 2D model incorporates curvilinear functions for investment and consumption out of unearned income. To bring in fiscal policy, I make use of a rule with either (1) dual targets of capacity utilization and public production, or (2) a balanced-budget target. Next, I add discrete jumps and policy-regime switches to the model in order to tell a story of a financial crisis followed by a move to fiscal austerity. Then, I return to the earlier model and add three more variables and equations: (1) I model the size of the privateand public-sector labor forces using a constant growth rate and account for their social reproduction by introducing an unemployment-insurance scheme; and (2) I make the markup endogenous, allowing its rate of change to depend, in a possibly nonlinear way, on capacity utilization, the real wage relative to a fixed norm, the employment rate, profitability, and the business sector's desired capital-stock growth rate. In the conclusion, I comment on the implications of my results for various policy issues.
\end{abstract}

Keywords: Financial Crisis; Post-Keynesian Economics; Fiscal-policy Rule; Dynamical System; Markup Dynamics; Kalecki-Steindl Model of Effective Demand; Hyman Minsky; Automatic Stabilizers; Growth Cycles; Budget Deficit; Capacity-utilization Targeting Rule; Historical Time; Policy Regime Switches; Keynesian Kaleidics; Chartalism; Distributive Curve

JEL Classifications: E12, E32, E62, J65 


\section{INTRODUCTION}

Recently, the use of fiscal policy has been a topic of concern in much of the world. Fiscal austerity measures in Europe have been heavily criticized, and many countries have been more open than in the recent past to a major role for discretionary fiscal policy.

In public discussions and debates, many observers have wondered whether a fiscalstimulus plan could actually reduce the government's budget deficit (DeLong and Summers 2012). Many also worry that recent fiscal-austerity plans will only bring higher deficits. Issues of this kind involve endogenous changes in tax revenues that occur when output, markups, financial fragility, and other variables are affected by changes in policy. Few would disagree that various paradoxes of austerity or stimulus might be relevant, but such issues can still be clarified a great deal with the help of a complete heterodox model.

The models that follow build upon the work of Dutt (2010), Laramie and Mair (1996, 2001), Lavoie (2000), Palley (1998), Tcherneva (2012), and You and Dutt (1996) to incorporate fiscal policy into models in the broad modeling tradition of Kalecki (e.g., [1943] 1991) and Steindl ([1952] 1976). ${ }^{1}$ Previous work along these lines has focused mostly on equilibria, comparative statics, simple two-dimensional dynamics, and long-run fiscal stability. I extend this earlier work to focus on dynamical issues in a computable, nonlinear model with distributional and labor-force-size variables. Also, the models in this paper employ the chartalist view of modern money to help clarify policy issues relating to the dynamics of government debt and have the property of stock-flow consistency (Godley and Lavoie 2007; Tobin 1980).

The nonlinear features of the models presented below make use of contributions such as Kaldor's (1940) model of the business cycle and Goodwin's (1967) distribution and growthcycle model. Like Asada's (1987) and Goodwin's (1990) Keynesian models of fiscal policy and business-cycle stabilization, the models in this paper combine nonlinear dynamics with nonclearing markets.

The first model combines a differential equation for capacity utilization based largely on Kaleckian and Steindlian economic principles with a feedback rule for fiscal policy of the same

\footnotetext{
${ }^{1}$ Kaleckian models were recently featured in a special issue of Metroeconomica. See Dutt (2012b) and other articles in the same issue. Paladini (1989) is a helpful account of Kalecki's work on fiscal policy.
} 
general type proposed by Phillips (1954). A linear version of this model is developed in section 2 of this paper. Nonlinearities in the consumption and investment functions are introduced in section 3. The dynamics of the nonlinear model, which are presented in the same section, appear as stable swirls or stable limit cycles when looked at in the form of vector plots and plots of solution pathways.

I experiment with the model of section 3 in the following section, constructing a stylized historical example and comparing the dynamics of the economy under two possible policy rules: (a) dual targets of capacity utilization and public production ${ }^{2}$; and (b) a balanced-budget target. The example highlights the sorts of dynamic paths that might result from a Minskyan financial crisis (Minsky [1986] 2008). The financial shock in the example is generated by a model of jump dynamics, in which the rate at which crises occur per unit of time depends on endogenous financial-fragility and capacity-utilization variables. A loss of tax revenue occurs after the shock, bringing about a change in the fiscal-policy regime that proves to be very maladaptive. The regime change is triggered when the fiscal deficit reaches an institutional "ceiling" of the type mooted in Ferri and Minsky (1992).

In section 5, the model is extended with the addition of 1) an endogenous markup; 2) a public unemployment-insurance scheme, which allows us to more explicitly model social reproduction; and 3) a steadily expanding labor force. The resulting model has five dimensions (5D): capacity utilization $\mathrm{u}$, government production $\mathrm{p}$, the markup $\mathrm{m}$, and the sizes of the privatesector labor force If and the public-sector labor force $p l f$.

The simulations in section 6 portray the behavior of a 4D version of the 5D model, which is obtained by combining the equations for the labor-force variables If and plf. The behavior of the $4 \mathrm{D}$ system is illustrated using some example solution paths I have found numerically using standard software. These pathways may be interesting to many and are somewhat unusual in the literature. I should state the caveat that the computable examples developed herein are mostly meant only as illustrations of phenomena that are likely to be widespread in models constructed

\footnotetext{
${ }^{2}$ The terminology used for this type of public expenditure in the academic literature is often "government purchases of goods and services." This is useful terminology, but here we wish to emphasize the government's role in this model as a direct employer of workers who produce services of various kinds. The model in this paper contains no government outsourcing or procurement from the private sector, though it could be modified to include a separate variable for such purchases.
} 
in the same general vein. In fact, most of the qualitative results cannot be shown to be universal. ${ }^{3}$ However, many are robust to wide variations in the values used for various parameters. To provide numerical examples, I choose parameter values that are meant only to be realistic, not necessarily precise. What I report, then, are the results of something that might be thought of loosely as a "computational experiment." Of course, more serious efforts at exact quantification could potentially also be useful and informative.

Finally, I have for the most part eschewed "long-run" behavior, in a way that was especially important to Robinson (1981) and some of the other early "Kaleckians." In lieu of steady-state analysis or analysis of dynamics as $\mathrm{t}$ approaches infinity, I report medium- to longrun simulations of exact behavior in state space. This approach in principle has the advantage that it permits economists to analyze whether a policy will prove unsustainable over a long but reasonable period of time. Notably, for example, in keeping with the stock-flow-consistent modeling approach (Godley and Lavoie 2007; Tobin 1980), the techniques employed here keep track of the stocks of liabilities implied by the flows generated during a simulation run. (For the stock-flow-consistency properties of the model, see the table at the back of the paper.) The numerical-solution approach also enables one to get a sense of how rapidly a dynamical system will approach a terminal pathway, such as a limit cycle, provided one exists.

The sort of medium-to-long-run analysis discussed above offers an alternative, yet complementary, perspective on the extensive debates about stability in "Kalecki-Steindl models" of effective demand, as represented by, say, Bhaduri (2008) and Hein, Lavoie, and van Treeck (2012). On the one hand, concerns about stability are somewhat moot in this paper, since no stable equilibrium point is even claimed to exist under general conditions. Moreover, the models below have no equilibrium whatsoever at full or optimum capacity utilization. Such an equilibrium is lacking in part because the government sets a subpar capacity-utilization target. The latter feature of the model seems plausible in light of (1) theories from political economy arguing that business-owning classes tend to oppose policies that would bring sustained full employment, e.g., Kalecki ([1943] 1990) and Halevi and Kriesler (2000); (2) potential problems with "crashing into" a Robinsonian inflationary barrier ${ }^{4}$-i.e., reaching approximately 100 percent capacity utilization — when aiming at a high output target; (3) beliefs in unhelpful

\footnotetext{
${ }^{3}$ Compare with the rigorous, theorem-based approach in, e.g., Flaschel, Franke, and Semmler (1997), which states conditions that guarantee the existence of limit cycles, etc., for many nonlinear models.

${ }^{4}$ See Robinson ([1952] 1979, 11-24).
} 
doctrines of macro policymaking, such as "NAIRU"; and (4) ineluctable difficulties in finding and achieving any stable equilibrium.

While the fiscal policy target is not attained at a stable equilibrium point, fiscal policy is effective. That is, the value of the capacity-utilization target certainly affects the economy's path in the short, medium, and long runs. For example, for a large set of reasonable parameter values, the nonlinear 2D model developed in sections 3 and 4 generates example paths that eventually reach a permanent orbit around a high-capacity-utilization equilibrium. On the other hand, in more complicated examples, even asymptotic orbital stability ${ }^{5}$ is often elusive, in a way that we economists are not always eager to admit. Note, however, Richard Day's observation:

Take a deep breath, pause, and then recognize that many processes in natureincluding human nature in general and human economic nature in particular-are unstable! They are unstable in the precise mathematical sense of not converging to stationary, steady, or periodic states $(1994,46)$.

We will meet a number of such processes in section 6 below.

From a policy perspective, the dynamic issues raised here are due for an urgent discussion. As this paper is being written, numerous countries are said by some to be in fiscal crisis. The macroeconomic terms "adjustment" and "stabilization" are front and center in policy discussions, summit meetings, and so on. Some economists have argued that some troubled economies are stuck in "austerity traps," in which austerity budgets reduce growth, causing tax revenues to fall and deficits to escalate further. This is a good example of the principle that a policy that appears likely to stabilize the economy based on point-in-time logic can often lead to unsustainable outcomes. On the other hand, pro-austerity economists posit a different form of fiscal spiral, claiming that ongoing deficits will lead inevitably to slow growth and default, even in countries that possess their own currencies, owing to "crowding-out" and other purported side effects of government borrowing. This proposition is a different matter altogether. While chartalists (e.g., Wray 2004) and other Keynesians criticize such claims aptly, the issues involved can perhaps be further clarified within the context of a dynamic model such as the one developed below, and indeed I try to do so in section 4 and elsewhere in this paper.

Finally, the increasing concentration of household wealth and income has been cited by many as a key force behind financial instability and recessions around the world and vice-versa

\footnotetext{
${ }^{5}$ See Wiggins (2003, 9-10) for a definition.
} 
(e.g., Galbraith 2012; Palley 2002; Reich 2010). Proponents of this theory can cite abundant supporting evidence such as the steady decline in the labor income share that has taken place over the last 30 years in the United States (Jacobson and Occhino 2012). Hence, one can hope that a model featuring an endogenous income-distribution variable, such as the endogenous markup introduced in sections 5 and 6 , will be the most perspicuous type for a study focusing on fiscal policy, public insurance schemes, and financial crises.

\section{A LINEAR 2D VERSION OF THE MODEL: AGGREGATE DEMAND AND FISCAL POLICY RULES}

In this section of the paper, we develop the building blocks for the linear 2D version of the model and look at the effects of fiscal policy in the model.

\subsection{Cost Side: Prices and Distribution}

Only one good is produced by the private sector. ${ }^{6}$ The capitalist firms that produce goods within the private sector as well as households with wealth will be treated as if they were one sector to simplify the accounting. Collectively, they will be called the K-sector in this paper. This sector owns most of its capital stock $\mathrm{K}$, while the $\mathrm{P}$ (public) sector owns the rest as a passive investor. Assume that the $\mathrm{K}$ sector's portion equals $\mathrm{rK}$ where $.5<\mathrm{r}<1$. Profits are divided between the $\mathrm{K}$ and $\mathrm{P}$ sectors in proportion to their ownership of the capital stock. The capital stock depreciates at a rate of $\delta \mathrm{K}$ per unit of time, where $0<\delta<1$.

We will treat the consumption and investment goods as identical, so that real quantities of each can be compared using the same units. Let $\mathrm{G}$ equal the number of units of the good produced for investment purposes and $\mathrm{C}$ equal the number of units used for immediate consumption. Production in the $\mathrm{K}$ sector involves two factors of production and is accomplished using a fixed-input-coefficients technology. Capital requirements are given by the constraint

$$
\mathrm{C}+\mathrm{G}=\mathrm{U} \leq \mathrm{K}
$$

where $\mathrm{U}$ is the utilized portion of the capital stock. To simplify the algebra, we have assumed a ratio of 1 unit of required capital per unit of output; of course, this assumption will not affect the generality of our results.

\footnotetext{
${ }^{6}$ Discussions of the general perspective on industrial economics and organization adopted in this section are available in Eichner (1976) and Kenyon (1979).
} 
Next we normalize the goods variables in the equation and inequality above by dividing by $\mathrm{K}$ and using small letters to indicate normalized variables, yielding

$\mathrm{c}+\mathrm{g}=\mathrm{u} \leq 1$

where $\mathrm{c} \equiv \mathrm{C} / \mathrm{K}, \mathrm{g} \equiv \mathrm{G} / \mathrm{K}$, and $\mathrm{u} \equiv \mathrm{U} / \mathrm{K}$. The new variable $\mathrm{u}$ is a measure of capacity utilization. We assume that the inequality on the right side of the line above normally holds, meaning that the $\mathrm{K}$ sector normally produces with excess capacity, and can increase $\mathrm{c}$ or $\mathrm{g}$ at the margin without having to install new capacity. In what follows, it may help to qualify the inequality above with the proviso that $u$ could exceed 1 over the very short run during a period of unusually high demand.

The labor needs of the $\mathrm{K}$ sector are given in the following equation

$$
\mathrm{L}_{1}=\operatorname{luK}=1(\mathrm{c}+\mathrm{g}) \mathrm{K}
$$

Finally, for simplicity and to focus on short- and medium-term research questions, we leave out technological progress.

We assume that firms set prices by applying a markup to unit variable costs, giving us the following relationship

$$
\mathrm{pr}=(1+\mathrm{m}) \omega_{1} 1
$$

where $\mathrm{pr}$ is the price of a unit of $\mathrm{K}$-sector output, the markup $\mathrm{m}$ is determined by market structure, and $\omega_{1}$ is the K-sector nominal wage. By market structure we mean factors such as the number of producers in each industry, their ability to keep new competitors from entering their markets, and their bargaining power vis-à-vis labor. The assumption of constant costs is appropriate for a model in which there is chronic excess capacity. Finally, in this section and the next two, we take the markup $\mathrm{m}$ in the equation above to be a constant, implying that the division of private sector output between the $\mathrm{K}$ sector and wage-earning households is taken as given until section 5 .

The gross profit rate has a simple expression

$$
\pi=\mathrm{u}\left(\mathrm{pr}-\omega_{1} 1\right)=u \omega_{1} 1
$$

We will refer to the public sector as the P-sector. Like the K-sector good, the P-sector output is produced at constant returns to scale, but the latter is produced with labor and no other 
input. Normalized units of P-sector output, $\mathrm{p}$, are defined so that for any number of hours of government employment $\mathrm{L}_{2}$,

$$
\mathrm{p}=\omega_{2} \mathrm{~L}_{2} /\left(\omega_{1} 1 \mathrm{~K}(1+\mathrm{m})\right)
$$

where $\omega_{2}$ is the given nominal wage received by a worker in return for one unit of time as an employee of the $\mathrm{P}$ sector. Though sometimes seen as running afoul of the law of one price, a differentiated wage structure is frequently observed and can be theoretically accounted for by theories of internal or dual labor markets (e.g., Doeringer and Piore [1971] 1985, chapters 4 and 8).

Also, the nominal private sector wage variable $\omega_{1}$ could just as easily be dropped from the model by setting it equal to 1 and letting $\omega_{2}$ equal the relative wage of P-sector workers. However, we will retain the symbol $\omega_{1}$ for use in section 5 and 6 below.

To simplify our notation in what follows, we will sometimes use the letter s for the share of profits in $\mathrm{K}$ sector output. This parameter can be expressed

$$
\mathrm{s}=\mathrm{m} /(1+\mathrm{m}) \equiv \pi / \mathrm{u}
$$

\subsection{Demand Side: Household and Firm Behavior}

Net investment-good demand as a proportion of existing capacity (or the notional growth rate) is assumed to depend on capacity utilization and the profit rate

$$
\mathrm{g}_{\mathrm{d}}=\text { auton }+\sigma \mathrm{u}+\kappa(1-\tau) \pi
$$

where $\kappa>0$ and $\sigma>0$ and auton $\in \mathbb{R}$.

This investment function, or a very similar one, is a hallmark of the "Kalecki/Steindl" approach to aggregate demand (Dutt 1984; 1990, 57-59). ${ }^{7}$ Dutt argues that "when the utilization of capacity falls below the desired level, firms will want to increase the utilization and invest more slowly and conversely when the utilization is above the desired level." Moreover, "the level of output (as a ratio of capital stock) may signal to firms the strength of the market, exciting animal spirits as in accelerator models" $(1990,58)$. In explaining the inclusion of the profit rate in the same function, Dutt points out that "Kalecki's analysis implies that the rate of profit can affect investment by affecting profit expectations...but also higher profits allow greater business

\footnotetext{
${ }^{7}$ For empirical tests, see Bhaskar and Glyn (1995) and Lavoie, Rodríguez, and Seccareccia (2004).
} 
saving, and thus (given credit market imperfections) ease the financial constraints to investment" $(1990,57) .^{8}$

In what follows, we follow the convention of treating corporations and the households who own assets as one consolidated sector. This simplification allows us to keep the math and accounting simple, but should not affect our main results in any way.

Turning our attention to households, suppose that consumption demand, $\mathrm{c}_{\mathrm{d}}$, depends on after-tax retained profits, interest, and $\mathrm{K}$-sector and $\mathrm{P}$-sector wage payments, respectively, in the following way

$$
\mathrm{c}_{\mathrm{d}}=(1-\tau)(\chi(\mathrm{r} \pi+\mathrm{ib})+(1-\mathrm{s}) \mathrm{u}+\mathrm{p})
$$

where $\tau<1$ is the tax rate on all income, $\chi$ is a positive constant, $\mathrm{r}$ is the retention ratio, $\mathrm{i}$ is the real interest rate on P-sector bills, and b is the amount of bills held by wealth-owning households in real terms. Of course, $c_{d}$ and $b$ are normalized in terms of units of capital, and, as we have seen before, so are $\pi$ and p. Also, note that interest on bills is credited continuously. Equation (4) assumes that workers in both sectors have a marginal propensity to consume out of disposable income of 1; this is meant as a simplification, though it has some empirical validity, even in societies with substantial middle classes. ${ }^{9}$

To obtain total private-sector output demand, we use the following identity

$$
\mathrm{u}_{\mathrm{d}} \equiv \mathrm{c}_{\mathrm{d}}+\mathrm{g}_{\mathrm{d}}+\delta
$$

It is given that the $\mathrm{K}$ sector owns a fraction $\mathrm{r}$ of its capital stock. To model the asset demands of households with wealth, we use the following demand function

$$
\begin{aligned}
& b^{d}=\beta(i)>0 \\
& \beta^{\prime}(i)>0
\end{aligned}
$$

along with Walras's law, which in this case dictates that

$$
\mathrm{w} \equiv \mathrm{r}+\mathrm{b}^{\mathrm{d}}+\mathcal{M}^{\mathrm{d}}
$$

\footnotetext{
${ }^{8}$ There has been some disagreement in the literature about how best to model the effects of distributional variables on investment, especially in models in which such variables are endogenous, such as the 5D model discussed below. Notable among the critiques of the Kaleckian approach is Bhaduri and Marglin (1990), which advocates the specification $\mathrm{f}(\mathrm{s}, \mathrm{u})$, rather than $\mathrm{f}(\pi, \mathrm{u})$. For a detailed discussion and defense of specifications of the latter form, see Lavoie (1995, 795-802). This paper will have to leave to one side the issues raised by these and similar articles, without seeking to prejudice further discussion about the best way to model the effects of income distribution on investment.

${ }^{9}$ Bowles and Boyer (1995) and Stockhammer, Onaran, and Ederer (2009), and the works cited in those articles, investigate empirical claims regarding consumption functions similar to equation (4).
} 
implying that the interest rate determines what fraction of their wealth $\mathrm{w}$ that K-sector households choose to hold in the form of government bills $\mathrm{b}$ versus money $\mathcal{M} .{ }^{10}$ The values of all of these stock variables are taken as given at any point in time and are denominated in goods, using the same normalization as before. ${ }^{11}$

Before we study the dynamic adjustment processes involved when the economy is not in a steady state, we wish to find an expression that defines a static equilibrium in the model made up of equations (3)-(7). Using the equilibrium condition

$\mathrm{u}=\mathrm{u}^{\mathrm{d}}$

gives us the relationship

$\mathrm{u}=$ auton $+\sigma \mathrm{u}+(1-\tau) \kappa s u+\delta+(1-\tau)(\chi(\mathrm{rsu}+\mathrm{ib})+(1-\mathrm{s}) \mathrm{u}+\mathrm{p})$

We can then solve this equation to obtain a multiplier-type relationship between public spending, $\mathrm{p}$, and capacity utilization, $\mathrm{u}$

$\mathrm{u}=($ auton $+\delta+(1-\tau)(\mathrm{p}+\chi \mathrm{ib})) /(1-\sigma-(1-\tau)(\mathrm{\kappa s}+\chi \mathrm{rs}+(1-\mathrm{s}))$

From this equation, we find that $\mathrm{du} / \mathrm{dp}>0$ if and only if

$$
\sigma+(1-\tau)(\kappa s+\chi \mathrm{rs}+(1-\mathrm{s}))<1
$$

It is common to refer to parameter restrictions of this general type as Keynesian stability conditions (see Kaldor 1940).

The following identity is a K-sector budget constraint implying that the private sector balance (on the left side of the equation) equals K-sector income minus K-sector consumption minus investment

$$
\begin{gathered}
\text { privbal } \equiv(1-\tau)(i b+r \pi)-(1-\tau) \chi(\mathrm{ib}+\mathrm{r} \pi)-g \\
\equiv(1-\tau)(1-\chi)(i b+r \pi)-g \equiv \dot{b}+\dot{\mathcal{M}}
\end{gathered}
$$

The last equality follows from the notion that the rate of change in the K-sector's financial assets at any given point in time is equal to that sector's financial balance. In equation (9) and throughout this paper, an overdot symbol will be used to indicate differentiation by time, t.

The financial portion of the model as presented so far is unfortunately rather crude and rudimentary; it could easily be modified to encompass a more detailed treatment of financial

\footnotetext{
${ }^{10}$ For a stock-flow consistent post-Keynesian model with a more detailed financial sector, see Dos Santos and Zezza (2008), and for a more comprehensive account of the role of money in Kaleckian models, see Hein (2008).

${ }^{11}$ Money serves an important role here, but for simplicity we treat it here as if it were inflation indexed. This assumption does not matter in this model, as the results do not rely on "money illusion," real-wealth effects, and the like. Like other aspects of this model, the monetary system described in this section fits well in an environment with rather low and stable inflation and interest rates.
} 
instruments and institutions. The simplifications involved will allow the paper to focus on broad fiscal policy issues.

\subsection{The P Sector: Monetary and Fiscal Policy}

We assume that the $\mathrm{P}$ sector sets an interest rate target, then meets all market demand for bills, as determined by equation (6). The "accommodative" asset-supply behavior used to implement this policy, which resembles the behavior of a modern central-bank trading desk (Moore 1988), can be summarized by the following three relationships

$$
i=\bar{\imath} ; \quad b=b^{s}=b^{d} ; \mathcal{M}=\mathcal{M}^{s}=\mathcal{M}^{d}
$$

For the sake of simplicity, we will assume throughout this paper that the target $\bar{l}$ is a constant.

The fixed interest rate target in (10), together with the bond demand function (6) allow us to set $\dot{b}=0$, yielding the following version of equation (9)

$$
\text { privbal } \equiv(1-\tau)(1-\chi)(i b+r \pi)-g=\dot{\mathcal{M}}
$$

In other words, the sectoral surplus (deficit) as a percentage of the capital stock comes in the form of net additions to (reductions in) the normalized stock of money.

In addition to emitting financial liabilities, the government collects taxes, as mentioned above. For simplicity, we assume that all income is taxed at a constant tax rate $\tau$. This tax on all profits, wages, and interest is collected on interest and profits directly from the $\mathrm{K}$ sector and on wages from $\mathrm{K}$ - and P-sector employees.

We include the P sector's receipts of distributed profit income $(1-r) \pi$ along with income tax revenue $\tau(u+p+i b)$ as credits in our definition of the government budget deficit. The corresponding debits are public spending $\mathrm{p}$ and interest payments $\mathrm{ib}$ on the national debt, leading to the following identity

$$
d f \equiv \mathrm{p}+\mathrm{ib}-(1-\mathrm{r})(1-\tau) \pi-\tau(\mathrm{u}+\mathrm{p}+\mathrm{ib}) \equiv \dot{b}+\dot{\mathcal{M}}
$$

Again, when we assume that the government holds the interest rate target constant, we can set $\dot{b}=0$, which in this case yields the following revised version of equation (12)

$$
d f \equiv \mathrm{p}+\mathrm{ib}-(1-\mathrm{r})(1-\tau) \pi-\tau(\mathrm{u}+\mathrm{p}+\mathrm{ib}) \equiv \dot{\mathcal{M}} \equiv \text { privbal }
$$

The last equality is a consequence of equation (11) and means that the P-sector deficit is equal to the private sector balance, which is to be expected in a two-sector model.

Note that by using the identity $\mathrm{w} \equiv \mathrm{b}+\mathcal{M}$, differentiating by $\mathrm{t}$, and using (12) and (13), one can obtain 


$$
\dot{w} \equiv \dot{\mathcal{M}} \equiv d f
$$

which shows that government deficits increase wealth on K-sector balance sheets. The trivial Ksector asset-allocation decision given in equations (6) and (7) merely determines how its nontangible wealth is divided between two assets in our simplified economy: bills and money. The equations in (6), (7), (10), and (13) amount to something that at least vaguely represents a chartalist monetary system. ${ }^{12}$

Given our analysis above, an increase in public spending will increase the budget deficit over the short run if and only if $\partial d f / \partial \mathrm{p}=(1-\tau)-(((1-\mathrm{r})(1-\tau) \mathrm{s}+\tau)(1-\tau)) /(1-\sigma-(1-\tau)(\kappa \mathrm{s}+\chi \mathrm{rs}+(1-\mathrm{s})))>0$

There are then some dynamic implications of the model for fiscal policy rules. ${ }^{13}$ Consider, for example, the following balanced-budget targeting rule:

$$
\dot{p}=f_{1}(p) \equiv-\alpha_{1} d f
$$

where $\alpha$ is a constant. The notation $f_{i}()$, where $i$ is a positive integer, is used throughout this paper to indicate a real-valued function with continuous partial derivatives. Equation (14) is a balanced-budget targeting rule. Given that policy is set according to this rule, we have the stability condition

$$
\begin{aligned}
f_{1}^{\prime}(p)=-\alpha_{1}((1-\tau)-(((1-r)(1-\tau) s+\tau)(1 \\
-\tau)) /(1-\sigma-(1-\tau)(\kappa s+\chi \mathrm{rs}+(1-\mathrm{s}))))<0
\end{aligned}
$$

which is equivalent to the condition above for spending increases to increase the deficit. On the other hand, when the system possesses an equilibrium, the capacity-utilization targeting rule

$$
\dot{p}=f_{2}(p) \equiv-\alpha_{2}\left(u-u_{T}\right)
$$

is stabilizing in this simple model if

$$
f_{2}^{\prime}(p)=-\alpha_{2}(1-\tau) /(1-\sigma-(1-\tau)(\kappa s+\chi \mathrm{rs}+(1-\mathrm{s})))<0
$$

which will be true whenever the parameter values are such that increases in public spending result in increased capacity utilization.

\footnotetext{
${ }^{12}$ As examples of the literature on chartalism, see Wray (2004) for more details on the theory, practice, and institutions of this system or, for a brief synopsis, Tcherneva (2006, especially 77-84).

${ }^{13}$ Fiscal policy rules were originally developed by A. W. Phillips (1954). Phillips's papers on this subject are discussed in Turnovsky (2011).
} 


\section{INTRODUCING A KALDORIAN INVESTMENT FUNCTION AND A NONLINEAR CONSUMPTION FUNCTION}

We now wish to explore the effects of adding some nonlinearities to the model. First, we add nonlinearities to our earlier investment function (3). We make use of a shape introduced to investment functions by Kaldor (1940) in the context of a business cycle model. The general form of our new function is this:

$$
\begin{gathered}
g_{d}=\text { auton }+f_{3}\left(\mathrm{u}-u^{e q}\right)+\kappa(1-\tau) \pi \\
f_{3}^{\prime}>0
\end{gathered}
$$

In the modeling exercises below, the nonlinear form of this function will sometimes help to generate a stable limit cycle when the Keynesian stability condition mentioned above is violated at the steady-state equilibrium point. Steindl himself noted the relevance of such destabilizing forces in the context of his model of aggregate demand ([1952] 1976, xiv). The computable examples analyzed in this section will use the arc tangent functional form $f_{3}(u)=\varphi^{*} \arctan (\gamma \mathrm{u})$, an example of which is illustrated in figure 1. (All figures are located in a separate section at the end of paper.)

Next, our nonlinear consumption function includes a concave function of K-sector income, with the constant $\mu$ performing the role of the elasticity of consumption of that sector with respect to its income (after-tax retained profits plus after-tax interest earned on government bills)

$$
\begin{aligned}
& \mathrm{c}_{\mathrm{d}} \equiv \mathrm{c}_{\mathrm{k}}+\mathrm{c}_{\mathrm{w}}=\chi((1-\tau)(\mathrm{r} \pi+\mathrm{ib}))^{\mu}+(1-\tau)((1-\mathrm{s}) \mathrm{u}+\mathrm{p}) \\
& 0<\mu<1 ; \chi>0
\end{aligned}
$$

Using the nonlinear behavioral functions (16) and (17), the income-expenditure relationship (5) becomes

$$
\begin{aligned}
& \mathrm{u}_{\mathrm{d}} \equiv \mathrm{g}_{\mathrm{d}}+\mathrm{c}_{\mathrm{d}}+\delta=\text { auton }+\mathrm{f}_{3}\left(\mathrm{u}-\mathrm{u}^{\mathrm{eq}}\right)+\kappa(1-\tau) \mathrm{su}+\delta+\chi((1-\tau)(\mathrm{r} \pi+ \\
& \mathrm{ib}))^{\mu}+(1-\tau)((1-\mathrm{s}) \mathrm{u}+\mathrm{p})
\end{aligned}
$$


As in the linear model developed above, equilibrium effective demand is determined by the equation

$$
\mathrm{u}=\mathrm{u}_{\mathrm{d}}
$$

When this condition holds, goods are being produced and sold at the same rate that incomes are being paid. Rarely can we obtain a closed-form expression for $\mathrm{u}$ from this equation. However, given a somewhat arbitrary parameterization, we can illustrate the determination of equilibrium and the multiplier effect with a diagram. Specifically, we assume that the profit share $\mathrm{s}=1 / 6$ (i.e., $\mathrm{m}=.2$ ), the retention ratio $\mathrm{r}=.85$, the investment function uses the arc tangent functional form discussed above with a coefficient $\kappa=.05$ on the profit variable, the incomeelasticity of corporate sector consumption $\mu=.65$, and the income tax rate $\tau=.2$.

We use this parameterization to numerically solve equations (18) and (19), with capacity utilization $\mathrm{u}$ being a function of public spending $\mathrm{p}$, which we treat as an exogenous variable for the moment. Figure 2 shows the resulting nonlinear fiscal "multiplier" relationship.

We can also use the nonlinear model to illustrate the dynamics of a system in which public spending is endogenously determined, and all variables adjust toward equilibrium only at a finite rate if at all. Assume the government uses $\mathrm{p}$ as a policy instrument to stabilize capacity utilization but tries to maintain spending roughly equal to a target $\mathrm{p}_{\mathrm{T}}$.

$$
\dot{p}=f_{4}(p) \equiv-\left(\alpha_{2}\left(u-u_{T}\right)+\alpha_{3}\left(p-p_{T}\right)\right)
$$

The second part of this rule is a term that tends to draw public spending $\mathrm{p}$ toward some level reflecting non-macro policy goals and a need for balance in output levels when the private sector economy is not too far from full capacity utilization.

In our $2 \mathrm{D}$ system, this rule is combined with a differential equation for the level of capacity utilization

$$
\dot{u}=\alpha_{4}\left(u_{d}-\mathrm{u}\right)
$$

to obtain a dynamic system made up of (20) and (21), with $\mathrm{u}_{\mathrm{d}}$ defined by the equation (18). The equation represents an adjustment process which might involve, among other things, adjusting inventories; discarding dated, spoiled, or obsolete merchandise; opening and closing production lines and facilities; working off backlogs of orders; recruiting and hiring new personnel, etc. For the parameter values used in our illustration, the system possesses a steady state at $\mathrm{p}=.2$ and $\mathrm{u} \approx$ .67449 . These values turn out to be of limited significance in the dynamic examples studied 
below, as they are the coordinates of an unstable equilibrium point. (See the appendix at the end of the paper for a complete list of the parameters and functional forms used in the computable models in this paper.)

Three figures depict the dynamics of the system of equations (20) and (21). Figure 3 is a vector field graph and shows the interaction of the private sector output variable $\mathrm{u}$ (on the vertical axis) with the government production variable $\mathrm{p}$ (on the horizontal axis).

Figure 4, on the other hand, shows the same system in streamline form. Selected pathways are depicted in blue lines, with arrows indicating the direction of movement. The speed-of-adjustment parameters for these figures have been chosen to visually highlight the presence of a limit cycle within the portion of the state space shown in the figure. The cycle lies between inward-spiraling arrows toward the edges of the figure and outward-spiraling arrows toward the center of the figure. It is apparently a stable (supercritical) limit cycle.

Next, to show how the convergence process works, we depict one particular pathway, starting at an arbitrarily chosen point in $u-p$ space. As seen in figure 5 , the path in question begins at capacity utilization of approximately .57 , with government production equal in value units to the output of approximately .15 times private sector capacity. The adjustment process converges asymptotically but rather gradually toward the limit cycle that was seen less clearly in figure 4 .

The qualitative properties of this system were rather robust to variations in the parameters. Moreover, adjustment toward the limit cycle was rather slow for a wide range of parameter choices. A loss of asymptotic stability and the birth of a limit cycle in state space can be observed in a series of plots similar to figure 4 when the model is repeatedly solved while the constant $\gamma$ inside the arc tangent term in the investment function is gradually increased.

Hence, the picture above depicts an economy that is virtually in the doldrums, but also one in constant motion, without a reliable guide to the future. Even the equilibrium point (which is located at the center of the figure) is completely irrelevant, because it will never be approached.

\section{CYCLES AND CATACLYSMS ${ }^{14}$}

\footnotetext{
14 "These things were not cycles, but cataclysms" (Shackle [1972] 1992, 439).
} 
In this section, we provide a concrete example of the kind of policy story that can be told with a model of this type. We can compare the behavior of the model from the previous section with a model in which the $\mathrm{P}$ sector targets a balanced budget, rather then a particular level of capacity utilization and/or public production. The analysis developed in this section will hint at the adaptability of heterodox models such as the one presented above to analyzing policy-regime change, epochal and extreme financial shocks, irreversible dynamics, failures of stabilizing forces, and other nonequilibrium themes that frequently resurface in the history of an economy. For example: Ferri $(2010,207)$ has pointed out that some of the properties typical of nonlinear systems, including endogenous fluctuations and chaotic motion, make them "a natural humus in which [Minskyan] Ponzi phenomena can occur." He elaborates that in such dynamic models, "an extreme event...characterized by Knightian uncertainty...can become a dynamic possibility that is not excluded by definition, as it is in the rational expectation theory."

We will see an illustration of such phenomena in subsection 4.2 below. First, in section 4.1, we develop the dynamic properties of the model under a balanced-budget targeting regime.

\subsection{The Dynamics of “Treasury” Views of Fiscal Policy in the 2D Model}

We begin our comparison of alternative fiscal policy rules by recalling that equation (14), the balanced-budget-targeting rule, was

$$
\dot{p}=f_{1}(p) \equiv-\alpha_{1} d f
$$

Rules like this one tend to be adopted only when authorities are implementing a program of "shock therapy." However, the function above could easily be changed so that the target for the budget deficit was some nonzero constant times output.

If we combine the differential equation for income-expenditure adjustment (21) with this revised policy rule, then the dynamics are qualitatively and dramatically different than when the capacity utilization target is used. The system loses all stability. Using the same set of parameter values as in the previous section, we find the vector plot shown in figure 6 for the 2D system under the balanced-budget targeting rule.

The figure reveals a dynamic of nearly futile and eventually disastrous budget cuts. The region of nearly horizontal arrows on the right side of the figure shows the $\mathrm{P}$ sector cutting spending in an effort to balance the budget. This process may temporarily lead to a slight increase in capacity utilization $u$ as the economy follows one of the pathways leftward toward 
lower P-sector spending, but ultimately, as balance is achieved, capacity utilization plummets down the diagonal "gully" on the other side of the figure. The deficit does not significantly improve even along the beginning of this pathway. Finally, as output begins to drop downward on the left side of the figure, tax revenues from worker households and the $\mathrm{K}$ sector drop in tandem with output. One could think of this pathway as a catastrophic one. It reveals that the benefits of public spending cuts for the fisc and the economy are problematic at best in this model. ${ }^{15}$

\subsection{Modeling a Financial Crisis Followed by an Austerity Policy}

Suppose we have the following scenario. It is not meant to be taken literally, but rather as a schematic illustration of one possible path of the variables in real historical time. Suppose that the economy is evolving along the lines shown in Figures 3 or 4, orbiting the steady state point and approaching a limit cycle. Then, at a random time, a financial shock occurs, leading to a sudden drop in capacity utilization. One possible example would be a banking crisis followed by a bank holiday of sufficient length to disrupt a wide swath of the economy. ${ }^{16}$

A discrete-jump model seems well-suited to analyze the kinds of changes that Shackle referred to as "kaleidic" shifts (1974, 32-49; [1972] 1992, 55-59 and 427-442). Shackle used the concept of kaleidics as a way of pointing out that variables such as asset prices were based on precarious expectations and hence that a seemingly minor bit of arriving information (say, news

of a bank default) could lead to a "landslide" of changes in both expectations and the economy. ${ }^{17}$ He argued (1974, 48-49) that the emphasis on such ideas in, e.g., Keynes (1937), complemented relatively mechanical models of the trade cycle, such as Kaldor (1940), that made investment a smooth, deterministic function of tangible and gradually changing economic quantities. It is meant to perform a similar role here.

The occurrences of such a rare event could be modeled using jump dynamics governed by a conditional Poisson process (Feller 1966, 10-15). The event would occur at random intervals in continuous time, at a rate of $\lambda$ events per unit of time, where

\footnotetext{
${ }^{15}$ This result contrasts in some respects with the results in Wolfstetter (1982), in which a "classical" model is used as an alternative to a Keynesian one.

${ }^{16}$ See Minsky ([1986] 2008) and Wolfson (1994) on financial crises and their genesis.

${ }^{17}$ For the landslide metaphor, see Shackle ([1972] 1992).
} 
$\lambda=\lambda(\mathrm{f}, \mathrm{u})$

$\partial \lambda / \partial \mathrm{f}>0 ; \partial \lambda / \partial \mathrm{u}<0$

where the $\lambda($,$) is a continuously differentiable, real-valued function and \mathrm{f}$ is a measure of financial fragility. Minsky's financial fragility hypothesis argues that fragility builds up endogenously over time, increasing the risk of a crisis, which is ultimately sparked by the failure of a major bank, or some similar event. The fragility variable $f$ could itself be a function of various endogenous variables, such as the following

$\mathrm{f}=\mathrm{f}_{5}\left(\theta \mathrm{p}, \mathrm{t}-\mathrm{t}_{-1}, \mathrm{u}, \mathcal{M}+\mathrm{b}, \mathrm{r}(1-\tau) \mathrm{d} \pi / \mathrm{dt}\right)$

$\partial \mathrm{f}_{5} / \partial \mathrm{x}_{1}<0 ; \partial \mathrm{f}_{5} / \partial \mathrm{x}_{2}>0 ; \partial \mathrm{f}_{5} / \partial \mathrm{x}_{3}<0 ; \partial \mathrm{f}_{5} / \partial \mathrm{x}_{4}<0 ; \partial \mathrm{f}_{5} / \partial \mathrm{x}_{5}<0$

$0<\theta<1$

where $\theta$ is the fraction of the public sector budget allocated to financial regulators and bank supervisors, and the first line after the equation indicates the signs of all five partial derivatives of $f_{5}$. The second through fifth arguments in the function $f_{5}$ are, respectively: the amount of time $\left(t-t_{1}\right)$ since the last occurrence of a financial crisis; capacity utilization $u$, which acts as a proxy for the phase of the business cycle; the ratio of safe assets to capital $(\mathcal{M}+\mathrm{b})$ on $\mathrm{K}$-sector balance sheets; and the rate of change of the after-tax retained-earnings ratio. ${ }^{18}$

Let $\Delta_{\mathrm{i}}$ be the magnitude of the sudden output drop that occurs during crisis i, i $=1,2$, $3 \ldots$, where the index $\mathrm{i}$ indicates the order in which crises occur. Assume that $\Delta_{\mathrm{i}}$ is drawn at random, according to a conditional probability measure $\mathrm{P}\left(\Delta_{\mathrm{i}} \leq \Delta \mid \mathrm{u}=\overline{\mathrm{u}}\right)$. To present this simple parable with only one crisis, there is no need to choose a specific measure $\mathrm{P} .{ }^{19}$ In any event, it would be difficult to estimate it, given the relatively low frequency of observed crises. ${ }^{20}$

\footnotetext{
18 On the rationale for including the latter variable, see Veblen ([1904] 1975, 177-267). For a useful attempt to construct an empirical measure of Minskyan financial fragility, see Tymoigne (2012).

${ }^{19}$ Technically, $\mathrm{P}$ could be any conditional probability measure whose support is a subset of the open interval ( $\left.-\mathrm{u}, 0\right)$ on the real line (see Feller 1966, 44, footnote and 154-159).

${ }^{20}$ In fact, this distribution might be for all practical purposes unknowable, implying Keynesian uncertainty about the size of future output shocks, as in, for example, Keynes (1937).
} 
Jumps take place in an infinitesimal increment of time, during which the normal dynamics of the system, as given by the differential equations (20) and (21), do not apply. Let $t_{0}$ be the point in time when the crisis occurs. At that point, the economy moves a discrete distance downward in the state space all at once. Its movement traces a vertical, right-differentiable path in state space as a function of the time variable $t$. Hence, $u$ falls, but $p$ does not change by a discrete increment at time $t_{0}$.

Once a jump has occurred, capacity utilization $u$ is lower than it was the moment before the rare event. What happens next? The normal dynamics developed in section 3 again govern the system for $\mathrm{t} \geq \mathrm{t}_{0}$, but with the economy much farther away from the steady state than before. For example, the post-shock coordinates $\left(\mathrm{p}\left(\mathrm{t}_{0}\right), \mathrm{u}\left(\mathrm{t}_{0}\right)\right)$ for the economy might lie in the lower half of figures 3 , where the arrows point in different directions. In fact, many of the aqua or blue vectors there point almost straight to the right, implying that public spending would be rising rapidly while capacity utilization barely increased. This path in state space could become politically unsustainable due to rising budget deficits and/or an imbalance between the outputs of the public and private sectors. Let us imagine that this situation leads to a hurried and illconsidered change to fiscal-policy stringency.

Specifically, suppose that the fiscal policy rule is changed to the balanced-budget targeting rule (14). To make this idea more formal, we could assume the existence of an "institutional thwarting rule" (Ferri and Minsky 1992), stating that whenever the budget deficit reaches a particular "ceiling" level, the government switches to policy rule (14), causing a structural shift from the dynamics in figure 3 to those shown in figure 6 .

Given what we saw in section 4.1, it is not hard to see that such a policy-regime switch would be destabilizing. The economy would almost literally reverse course after the change, moving to the left along a pathway such as one of those in the lower half of figure 6 . Hence, during the attempt to balance the government budget, the economy would find itself in what could only be called an austerity trap, heading for a collapse in output, diagonally and to the left in that figure.

\section{THE 5D MODEL: ADDING ENDOGENOUS MARKUP DYNAMICS AND AN UNEMPLOYMENT INSURANCE PROGRAM}


So far, we have not made the markup $m$ endogenous. Rather, we have held it constant, assigning a value of $\mathrm{m}=.2$ in our simulations. Also, the model as developed so far in this paper has considered no approaches to income or output stabilization other than two alternative policy rules for government production. To remedy these two shortcomings in the 2D model, we begin by adding three more differential equations to the model: one equation for the markup and two more to model the growth of the public- and private-sector workforces. This gives us five dynamically endogenous variables in all: $\mathrm{p}, \mathrm{u}, \mathrm{m}, \mathrm{plf}$, and $l f$. The introduction of an explicit model of the labor force's size enables us to add an unemployment insurance program that replaces a portion of the earnings lost by unemployed workers in both sectors.

\subsection{A Model of Markup Dynamics}

Goodwin (1967) developed a growth-cycle model of the interaction of the business cycle and distributional conflict. In his view, wages would rise fastest relative to productivity when employment was high. Those who followed have come to differing conclusions about the relationship between the functional distribution of income and various other commonly used variables. Among the numerous models that endogenize distribution are those of Bhaduri and Marglin (1990), Dutt (1990), Dutt (2012a), Lavoie (1995), and Flaschel and Skott (2006).

The possibilities for variables to include in a differential equation for $\mathrm{m}$ are perhaps endless. Hence, this section takes the approach of including "everything but the kitchen sink." This equation could be adaptable to a variety of institutional settings and theoretical perspectives with the use of appropriate parameter values:

$$
\begin{array}{r}
\dot{m}=\alpha_{5}\left[\alpha_{6} f_{7}\left(g_{d}-g_{\text {normal }}\right)+\alpha_{7}\left(\frac{1}{l(1+m)}-\text { wagenorm }\right)\right. \\
+\alpha_{8} f_{8}\left(u^{e q}-u\right)+\alpha_{10}\left(\pi_{\text {target }}-\left(\frac{m}{1+m}\right) u\right) \\
\left.+\alpha_{11} f_{9}(e-\tilde{e})\right] \\
\text { g }_{\text {normal }}, \text { wagenorm, } \mathrm{u}^{e q}, \pi_{\text {target }}, \tilde{\mathrm{e}}>0 ; f_{7}^{\prime} \geq 0 ; \mathrm{e} \equiv(\mathrm{p}+(1 /(1+\mathrm{m})) \mathrm{u}) / l f
\end{array}
$$

where e is the employment rate, and If is the $\mathrm{K}$-sector labor force. 
This equation encompasses five types of pressures on the markup $\mathrm{m}$, corresponding to each of the five additive terms within the square brackets. Starting with the first term in equation (22), the five effects are:

(1) Growth-rate effects: The first summand within the square brackets is a constant $\alpha_{6}$ times a function $\mathrm{f}_{7}$ of the difference between desired growth rate of the capital stock $g_{d}$ and a normal growth rate. A case could be made for assuming that $\alpha_{6}>0$ and that $\mathrm{f}_{7}$ is monotonically decreasing on the grounds that a business sector attempting to grow too quickly loses some of its pricing power, owing to an inability to develop new markets of sufficient size (Dutt 2012a, 442). Alternatively, one could argue for an upward sloping $\mathrm{f}_{7}$ function, on the post-Keynesian grounds that plans for rapid growth bring increased needs for internal funds (Eichner 1976, 55-107; Kenyon 1979). ${ }^{21}$

(2) Structuralist/Institutionalist rigidities, a Classical subsistence wage, etc.: The second summand in equation (23) is a function of the real wage and represents attraction toward a decent standard of living, a bargained-for labor share in private sector income, a classical social-subsistence wage, a partially rigid structure of relative wages and prices (Piore 1979), or some similar norm.

(3) Kaleckian markup dynamics: The third summand allows for changes in the markup to depend on capacity utilization. Dutt (1990, 231-232; 2012a, 441) notes two Kaleckian reasons why such a theory may seem reasonable: (1) industries consolidate when demand is low, leading to higher industry concentration ratios and hence a higher degree of monopoly; and (2) at low levels of $u$, firms have higher average fixed costs, inducing them to increase $m$ to restore profits per unit. $^{22}$

(4) Profitability targeting: The fourth summand in equation (23) is meant to embody the notion of a target for profitability $\pi$ (Lavoie 1995). A fall in $u$ will result in a lower $\pi$, as long as $\mathrm{m}$ remains unchanged. Hence, this term posits that in a period of low $\mathrm{u}$, firms may choose to raise $m$ in order to maintain profitability.

\footnotetext{
${ }^{21}$ See Dutt (1990, 64-65), Sawyer (1995, Chapter 10), and the references cited in those works for more discussion of the role of the growth rate in determining the markup.

${ }^{22}$ See also Kalecki ([1943] 1991, 126-129). Among the empirical studies that examine the magnitude and sign of the effect of the rate of economic activity on distribution within the broad tradition of Kalecki and Steindl are Hein and Vogel (2008; 2009) and Naastepad and Storm (2006-07). Additionally, Gordon (1995), Nikiforos and Foley (2012) and Tavani, Flaschel, and Taylor (2011) investigate the form of the nonlinearities in "distributive functions" of this type. Hanes (1996) is a relatively recent example of an historical study on this topic.
} 
(5) "Class conflict": The fifth summand in equation (23) shows a tendency for the distribution of income to tilt in favor of workers when the employment rate $\mathrm{e}$ is high. This idea is grounded in Goodwin's model of growth and distribution cycles (1967) and is an accepted idea within the tradition of radical political economy (e.g., Skott [1989, Chapter 8]). ${ }^{23}$

\subsection{Adding an Unemployment Insurance Program}

A society often provides a social benefit to workers who become unemployed. Given that our model features excess productive capacity and often results in cyclical dynamics, it seems appropriate to add a program similar to the unemployment insurance programs now in place in many countries. These programs are funded using general tax revenues and/or special payroll taxes and replace a percentage of the earnings lost when a worker becomes unemployed.

To augment our model to include such a program, we need to take account of its effects on consumption expenditures. We measure the labor force If in efficiency units. Specifically, If $=L F / 1 \mathrm{~K}$ where $L F$ is the given number of hours of labor time supplied by the workforce. Then, since private sector employment $\mathrm{L}_{1}=\mathrm{luK}$, a labor force $I f=1$ would be large enough to operate the capital stock at full capacity, i.e., with $\mathrm{u}=1$. We will set the parameters in the simulations below so that If $\geq 1$, to ensure that the limited supply of labor available to K-sector employers does not pose a separate constraint on output over and above that imposed by the size of the existing capital stock (Robinson [1952] 1979, 11-14).

The amount of unemployed labor is

$$
U C \equiv L F-\mathrm{L}_{1}
$$

Let $u c \equiv U C /(\mathrm{IK})$. Then dividing the equation above by $1 \mathrm{~K}$ yields $\mathrm{uc} \equiv I f-\mathrm{u}$

In our model, P-sector workers receive a real wage that is different from that paid to workers in the $\mathrm{K}$ sector. In this section, we will explicitly assume that this group forms a separate labor market with a labor force of size PLF. Workers laid off from jobs in either sector wait to be rehired by the sector in which they previously worked. Dividing the labor force into the two parts will allow us to assume that unemployment benefit payments in each sector per unemployed unit

\footnotetext{
${ }^{23}$ Several alternative formulations of this relationship and of heterodox markup dynamics in general are outlined in Dutt (2012a).
} 
of labor are paid in proportion to the corresponding wages $\omega_{1}$ and $\omega_{2}$. For a given set of labormarket institutions, this assumption could potentially be justified by the existence of (1) discrimination, (2) requirements for sector-specific human capital in many fields, and/or (3) labor-market institutions that ensure most positions are filled by promotion from within. ${ }^{24}$

The number of P-sector workers receiving unemployment compensation is equal to the $P U C \equiv P L F-\mathrm{L}_{2}$

To express the real value of income from unemployment benefits in terms of private sector output, we normalize the equation above using the relationship given in (2). That is, we divide all terms of the equation by $1 \mathrm{~K}(1+\mathrm{m}) \omega_{1} / \omega_{2}$. We then get

puc $\equiv$ plf $-\mathrm{p}$

where, of course, $p u c \equiv P U C \omega_{2} /\left(1 \mathrm{~K}(1+\mathrm{m}) \omega_{1}\right)$ and $p l f \equiv P L F \omega_{2} /\left(1 \mathrm{~K}(1+\mathrm{m}) \omega_{1}\right)$.

After this normalization, total unemployment benefit payments can be expressed $\rho((1-s) u c+p u c)$

where $\rho<1$ is the replacement ratio. All in all, unemployed public sector workers receive $\rho \omega_{2}$ for each unit of their labor that is not demanded by the P sector, and, similarly, the corresponding group of private sector workers receives a benefit payment equal to $\rho \omega_{1}$ per unit of labor supplied but not hired.

Since workers spend all of their pay on consumption goods as soon as they receive it, it is logical to assume that the unemployed also have consumption propensities equal to 1 . Finally, we assume that unemployment benefits are not taxable income. Given these assumptions, adding the unemployment insurance system to the model changes the consumption function (17) to

$\mathrm{c}_{\mathrm{d}}=\chi((1-\tau)(\mathrm{rsu}+\mathrm{ib}))^{\mu}+(1-\tau)((1-\mathrm{s}) \mathrm{u}+\mathrm{p}+\rho((1-\mathrm{s})(l f-\mathrm{u})+(p l f-\mathrm{p}))$

This revised equation can be used to obtain the following new version of the income-expenditure relationship (18), which includes the goods demand of unemployed people.

$$
\begin{aligned}
& \mathrm{u}_{\mathrm{d}} \equiv \mathrm{g}_{\mathrm{d}}+\mathrm{c}_{\mathrm{d}}+\delta=\text { auton }+\mathrm{f}_{3}\left(\mathrm{u}-\mathrm{u}^{\mathrm{eq}}\right)+\kappa(1-\tau) \pi+\delta+\chi((1-\tau)(\mathrm{r} \pi+\mathrm{ib}))^{\mu} \\
& +(1-\tau)((1-\mathrm{s}) \mathrm{u}+\mathrm{p}+\rho((1-\mathrm{s})(l f-\mathrm{u})+(p l f-\mathrm{p}))
\end{aligned}
$$

\footnotetext{
${ }^{24}$ Again, on the concept of dual and internal labor markets, see Doeringer and Piore ([1971] 1987).
} 
We allow both portions of the labor force to grow at a gradual rate.

$$
\begin{aligned}
\dot{l f} & =l f\left(g_{0}-g_{d}\right) \\
p \dot{l} f & =p l f\left(g_{0}-g_{d}\right)
\end{aligned}
$$

The constant $\mathrm{g}_{0}$ is the rate of labor-force growth. The $\mathrm{g}_{\mathrm{d}}$ term is subtracted so that $l f$ and $\mathrm{pl} f$ are both adjusted to allow for the growth of the capital stock, since consumption $\mathrm{c}_{\mathrm{d}}$ in equation (24) is normalized by $\mathrm{k}$.

We also modify the definition of the government deficit (13) to include the costs to the P sector of paying unemployment benefits, obtaining

$$
\begin{gathered}
d f \equiv \mathrm{p}+\mathrm{ib}+\rho((1-\mathrm{s})(l f-\mathrm{u})+(p l f-\mathrm{p}))-(1-\mathrm{r})(1 \\
-\tau) \pi-\tau(\mathrm{u}+\mathrm{p}+\mathrm{ib}) \equiv \dot{\mathcal{M}} \equiv \text { privbal }
\end{gathered}
$$

The 5 differential equations in the new system include the equation for adjustments in $u$ (21), the revised $\mathrm{AD}$ equation (18'), the markup-dynamics equation (22), the two equations in (24) for the labor force size variables, and the fiscal-policy-setting equation (20).

\section{SIMULATION RESULTS FOR THE FULL MODEL IN $\mathrm{p}, \mathrm{u}, \mathrm{m}$, and If}

In order to simulate the full model, I set the replacement ratio $\rho=.35$. To roughly balance the budgetary and multiplier effects of unemployment-benefit outlays, I reduced the public-sectorproduction target $\mathrm{p}_{\mathrm{T}}$ to .1 and increased the tax rate $\tau$ by .02 to .22 . I combined the private-and public-sector labor markets and set $\omega_{1}=\omega_{2}=1$, treating labor as a homogeneous numéraire good. As mentioned before, I set If, which now represents the size of the entire workforce, equal to 1.1 for $\mathrm{t}=0$. To center the system, I began by assuming that labor force growth was zero and solved for the equilibrium of the system. I obtained a value of $\mathrm{u}^{\mathrm{eq}}=0.7698086523314395$. To center the system around the equilibrium defined by this value and the new $\mathrm{p}_{\mathrm{T}}$, I set $\mathrm{u}_{\mathrm{T}}=\mathrm{u}^{\text {eq }}$ and plugged in values for $\mathrm{p}_{\mathrm{T}}, \mathrm{u}_{\mathrm{T}}, \mathrm{u}^{\mathrm{eq}}$ into equations $\left(18^{\prime}\right),(20)$, and $\left(22^{\prime}\right)$ below. Next, I set the laborforce growth rate $\mathrm{g}_{0}=.01$. The remaining parameter values used below are listed in the appendix and are similar to those used for the 2D model. For the markup-dynamics equation, I used the following version of (22), which assigns specific functional forms to the functions $\mathrm{f}_{7}, \mathrm{f}_{8}$, and $\mathrm{f}_{9}$ : 


$$
\begin{aligned}
& \dot{m}=\alpha_{5}\left\{\alpha_{6}\left[\frac{\left(g_{0}-g_{d}\right)^{3}-\left|\left(g_{0}-g_{d}\right)^{3}\right|}{2}\right]\right. \\
&+\alpha_{7}\left[\frac{1}{l(1+m)}-\text { wagenorm }\right]+\alpha_{8}\left(\alpha_{9}\left(u^{e q}-u\right)\right)^{5} \\
&+\alpha_{10}\left[\pi_{\text {target }}-\left(\frac{m}{1+m}\right) u\right] \\
&\left.+\alpha_{11} \frac{\left[\left((-1) \alpha_{12}(e-\tilde{e})\right)^{5}-\left|\left((-1) \alpha_{12}(e-\tilde{e})\right)^{5}\right|\right]}{2}\right\}
\end{aligned}
$$

The first term on the right side of this equation creates an asymmetric effect, in which strong growth of the capital stock relative to that of the labor force results in a falling markup, but on the other hand, relatively slow growth has no effect whatsoever on the markup. This effect can be reversed by using $\alpha_{6}<0$. On the other hand, the third term is a curvilinear, but monotonically decreasing, relationship and is illustrated in figure 7. Finally, the functional form used in the fifth term is illustrated in figure 8. It features rapid decreases in $\mathrm{m}$ at very high levels of the employment rate and is not unlike Goodwin's (1967) figure 1, except for our use of m rather than the real wage as the distributional variable.

Figures 9a through 13b depict various examples of pathways, which use an assortment of parameter values and initial conditions. Each number 9 to 13 corresponds to a simulation with one set of parameter values and given initial conditions, all of which are listed in the appendix. For each of these simulations, we report the results in two separate figures: figure (a) in each pair depicts the paths of public production $\mathrm{p}$, capacity utilization $\mathrm{u}$, and the markup $\mathrm{m}$, while the corresponding figure (b) displays three more variables: money $\mathcal{M}$, the budget deficit $d f$, and e, the employment rate. To start with, figures $9 \mathrm{a}$ and $9 \mathrm{~b}$ depict a simple example with Kaleckian pricing dynamics. That is, we use a version of equation $\left(22^{\prime}\right)$ that omits all but the third term, making the rate of change of $m$ depend only on the capacity utilization variable $u$. We also set the replacement rate $\rho$ for the unemployment insurance program equal to zero, so that the unemployed have no purchasing power.

Figure 9a reveals the simulated pathway in p-u-m space. The pathway starts with low markup $\mathrm{m}$, and spirals outward, with its fluctuations in capacity utilization $\mathrm{u}$ and public 
production $\mathrm{p}$ increasing in amplitude. The path begins to tip toward a more vertical position, so that $\mathrm{m}$ oscillates along with the other two variables. Gradually, the path flattens out again and climbs upward along the $\mathrm{m}$ dimension toward a stable limit cycle at which $\mathrm{m} \approx .25$. Meanwhile, as the economy approaches the limit cycle, the amplitude of the cyclical motions gradually falls.

Figure $9 \mathrm{~b}$ shows that the employment rate e oscillates within a range from a bit more than .5 to a little under 1 . At the same time, the budget deficit $d f$ oscillates at first between positive and negative values, then trends upward until it remains permanently above zero. The stock of money $\mathcal{M}$, rises from around 1 to around 2 by the end of the simulation period.

Figures $10 \mathrm{a}$ and $10 \mathrm{~b}$ reveal how the dynamics of the same system change when a greatly increased adjustment parameter is used in the differential equation for $\mathrm{m}$. A comparison of Figures 9a and 10a shows that the smooth, increasing path seen in the first figure has been transformed into one with a nearly vertical loop from modest levels of about 2 to just above 0 and then back up to about .9. The latter value for $\mathrm{m}$ implies that the labor share $\mathrm{s} \approx .53$ near the end of the pathway shown in figure $9 \mathrm{a}$.

A look at figure 10b shows a move from an outward spiral pattern to an inward spiral pattern midway along the simulated pathway. The new pattern features higher levels of e and $d f$ and ends with an abrupt takeoff of $\mathcal{M}$ and a fall in e. The shift in dynamics could just as well be described as a structural change from an unstable system to a stable one, except for the abrupt change of direction toward the end of the simulation. Actually, of course, no change in the parameters was made during the simulation.

Figures 11a and 11b show one example of a pathway for a model with a Goodwinian or "radical" model of markup dynamics. That is, the markup equation contains only the last term, meaning that the rate of change of $m$ depends only on e. The pathway spirals inward, with fluctuations in $p$ and $u$ decreasing in amplitude. This enables the economy to remain within a fairly small region of the figure over a number of cycles. However, $p$ trends downward from cyclical peak to cyclical peak. Then, $\mathrm{m}$ begins to rise more and more rapidly toward high levels, and progress in moderating the cycle in $\mathrm{p}$ and $\mathrm{u}$ slows down greatly.

Figure $11 \mathrm{~b}$ shows a tightening spiral pattern in e and $d f$. However, the spiraling pathway twists downward to lower and lower employment rates, eventually getting stuck below e $=.6$. Meanwhile, $\mathcal{M}$ rises continuously. 
Figures $12 \mathrm{a}$ and $12 \mathrm{~b}$ depict a system that uses all the terms in the markup-dynamics equation (22'), except for the "radical" term. In particular, I use a negative $\alpha_{6}$ parameter, which implies that firms increase their markups when they intend to grow rapidly, as argued by some post-Keynesians (see section 5.1). Moreover, I assign a value to this parameter that is rather high in absolute value. Figure 12a depicts the system spiraling slowly inward in the $\mathrm{p}$ and $\mathrm{u}$ dimensions and simultaneously downward toward lower levels of $\mathrm{m}$, where it appears to begin to tighten toward a stable limit cycle pattern at approximately $\mathrm{m}=.2$.

Figure $12 \mathrm{~b}$ shows that in this example, $d f$ begins with a swoop through negative values. It then fluctuates over time, but it stays positive for the remainder of the simulation. Once this change to continuous deficits occurs, $\mathcal{M}$ rises continuously, reaching a level of approximately 1.1 at the end of the pathway. Meanwhile, the amplitude of cycles in e and $d f$ decreases somewhat over time.

Figures $13 \mathrm{a}$ and $13 \mathrm{~b}$ depict a system that uses all but the last term in $\left(22^{\prime}\right)$. Figure $13 \mathrm{a}$ shows irregular fluctuations leading to a terminus where $\mathrm{p} \approx .04, \mathrm{u} \approx .78$ percent, and $\mathrm{m} \approx .20$. The first portion of the pathway (corresponding to $0 \leq \mathrm{t}<.6$ ) is not shown in the figure, but it features extreme movements, which carry the system through very high values for $\mathrm{m}(>1.8)$ and $\mathrm{p}$ (in excess of .4). Figure $13 \mathrm{~b}$ reveals that this system also has an erratic pathway in e- $d f-\mathcal{M}$ space.

\section{POLICY IMPLICATIONS AND FUTURE RESEARCH}

The foregoing results have some implications for the conduct of fiscal policy. None could be clearer than the negative results of section 4.1 on the stability of our nonlinear post-Keynesian model with a balanced-budget targeting rule for fiscal policy. Also, our model casts serious doubt on the notion that an ongoing tendency toward fiscal deficits leads to unsustainable dynamics of any kind in a system of state money. Figures 9b, 10b, and $11 \mathrm{~b}$ all show cases in which such a tendency leads to a rising stock of government liabilities relative to capital, but this ratio stays within reasonable bounds during simulations equivalent in length to a large number of complete business cycles. Indeed, fiscal stability is maintained despite the use of "activist" fiscal policy and a massive unemployment insurance program.

The dynamic pathways reported and discussed in sections 3, 4, and 6 and in the figures at the back of the paper do not offer a small set of clear and unambiguous lessons for policymaking. 
On the other hand, the varied possibilities themselves do suggest the existence of some kinds of pitfalls for policymakers who wish to stabilize the economy. First, the pathways generated by our nonlinear model would not be amenable to estimation using standard econometric techniques. Second, the dynamics of the economy can change dramatically, even when it appears that a modicum of stability has been attained - consider the sudden financial cataclysm of section 4.2 or the or the sudden jump in $m$ that occurs in figure 10a. Such simulated jumps can help account for discontinuous data, which cannot easily be modeled using standard linear approaches. Third, equilibrium analysis is not of much help in the process of steering or stabilizing an economy even in the simplified world of the model developed in this paper, which leaves out many nuances that are relevant in the real world. Our models feature a "socially constructed" equilibrium level of capacity utilization: one set by policymakers, who may or may not be trying to achieve full employment. In most of our examples, this equilibrium fails to attract the economy, despite the government's efforts to hit its target. Fourth, even when parameter values are such that the system adjusts toward a stable equilibrium, the adjustment process is often rather slow, making the long-run properties of the system somewhat academic.

Finally, it should be pointed out that while stabilization is problematic in the postKeynesian world, the capacity-utilization/public-production targeting rule combined with a system of unemployment insurance is somewhat effective in keeping the system from behaving erratically, except in our last example in the previous section. Moreover, when the dynamics of the economy involve a stable limit cycle, as in the 2D case shown in figures 3, 4, and 5 or in the $4 \mathrm{D}$ version illustrated in figures $9 \mathrm{a}$ and $9 \mathrm{~b}$, an adjustment of the policy-function parameters could, in principle, be used to lower the amplitude of the cycle or even change it into a stable equilibrium point. In practice, of course, it might be preferable to target a different output variable.

On the other hand, when the economy seems to be becoming unstable - as in the examples of a financial crisis (as in section 4), a "catastrophic" change in e, $\mathcal{M}$, and other variables (figure 10b), or an accelerating rise in $\mathrm{m}$ (figure 11a) - the best policy may be some form of rapid, but possibly temporary, shift in fiscal policy. If such a move successfully caused the economy to jump to an appropriate region of the state space, one in which change occurred slowly, it might orbit gently for a very long time before policymakers again needed to make an "adjustment." 
Future work to extend this model might include adding endogenous productivity growth and interest rates; more systematically looking at the effects of varying the parameter values used in the simulations; looking in more detail at the effects of alternative taxes and tax policies; incorporating section 4's model of financial crises into the full model; modeling inflation and policies to restrain it; comparing the advantages of a public employer-of-last-resort program visà-vis the unemployment insurance scheme of sections 5 and 6; studying the effects of secular rises in financial fragility; and looking at failsafe policies that might help during potentially catastrophic situations, or perhaps Prof. Shackle's cataclysms. 


\section{REFERENCES}

Asada, Toichiro. 1987. "Government Finance and Wealth Effect in a Kaldorian Cycle Model." Journal of Economics 47(2): 143-66.

Bhaduri, Amit. 2008. "On the Dynamics of Profit-led and Wage-led Growth." Cambridge Journal of Economics 32(1): 147-160.

Bhaduri, Amit, and Stephen Marglin. 1990. "Unemployment and the Real Wage: the Economic Basis for Contesting Political Ideologies." Cambridge Journal of Economics 14(4): 375393.

Bhaskar, V., and Andrew Glyn. 1995. "Investment and Profitability: The Evidence from the Advanced Countries.” In Gerald A. Epstein and Herbert M. Gintis (eds.), Macroeconomic Policy after the Conservative Era. New York: Cambridge University Press: 175-196.

Bowles, Samuel, and Robert Boyer. 1995. "Wages, Aggregate Demand, and Employment in an Open Economy: An Empirical Investigation." In Gerald A. Epstein and Herbert M. Gintis (eds.), Macroeconomic Policy after the Conservative Era. New York: Cambridge University Press: 143-174.

Day, Richard H. 1994. Complex Economic Dynamics. Volume I, An Introduction to Dynamical Systems and Market Mechanisms. Cambridge, MA: MIT Press.

DeLong, J. Bradford, and Lawrence H. Summers. 2012. "Fiscal Policy in a Depressed Economy." Conference draft. University of California, Berkeley and Harvard University.

Doeringer, Peter B., and Michael J. Piore. (1971) 1985. Internal Labor Markets and Manpower Analysis. Armonk, NY: M. E. Sharpe.

Dos Santos, Claudio, and Gennaro Zezza. 2008. “A Simplified 'Benchmark', Stock-Flow Consistent Post Keynesian Growth Model.” Metroeconomica 59(3): 441-478.

Dutt, Amitava. 1984. "Stagnation, Income Distribution, and Monopoly Power." Cambridge Journal of Economics 8(1): 25-40.

- 1990. Growth, Distribution, and Uneven Development. New York: Cambridge University Press.

—. 2010. "Government Spending, Aggregate Demand and Economic Growth." Preliminary draft prepared for presentation at the Eastern Economic Association annual meeting, New York, NY, February. Notre Dame, IN: University of Notre Dame. 
_ 2012a. "Distributional Dynamics in Post Keynesian Growth Models." Journal of Post Keynesian Economics 34(3): 431-451.

—. 2012b. "Kaleckian Growth Theory: An Introduction." Metroeconomica 63(1): 1-6.

Eichner, Alfred S. 1976. Megacorp and Oligopopoly: Micro Foundations of Macro Dynamics. New York: Cambridge University Press.

Feller, William. 1966. An Introduction to Probability Theory and its Applications. Vol. 2. New York: John Wiley \& Sons.

Ferri, Piero. 2010. "Growth Cycles and the Financial Instability Hypothesis (FIH).” In Dimitri B. Papadimitriou and L. Randall Wray (eds.), The Elgar Companion to Hyman Minsky. Northampton, MA: Edward Elgar.

Ferri, Piero, and Hyman P. Minsky. 1992. "Market Processes and Thwarting Systems." Structural Change and Economic Dynamics 3(1): 79-91.

Flaschel, Peter, Reiner Franke, and Willi Semmler. 1997. Dynamic Macroeconomics: Instability, Fluctuation, and Growth in Monetary Economics. Cambridge, MA: MIT Press.

Flaschel, Peter, and Peter Skott. 2006. "Steindlian Models of Growth and Stagnation." Metroeconomica 57(3): 303-338.

Galbraith, James K. 2012. Inequality and Instability: A Study of the World Economy Just before the Great Crisis. New York: Oxford University Press.

Godley, Wynne, and Marc Lavoie. 2007. Monetary Economics: An Integrated Approach to Credit, Money, Income, Production and Wealth. New York: Palgrave Macmillan.

Goodwin, Richard. 1967. “A Growth Cycle.” In C. H. Feldstein (ed.), Socialism, Capitalism and Economic Growth. New York: Cambridge University Press.

—. 1990. Chaotic Economic Dynamics. Oxford: Clarendon Press.

Gordon, David M. 1995. "Growth, Distribution, and the Rules of the Game: Social Structuralist Macro Foundations for a Democratic Economic Policy." In Gerald A. Epstein and Herbert M. Gintis (eds.), Macroeconomic Policy after the Conservative Era. New York: Cambridge University Press: 335-383.

Halevi, Joseph, and Peter Kriesler. 2000. "On the Limitations of Fiscal Policy: A Radical Kaleckian View." In Hassan Bougrine (ed.), The Economics of Public Spending: Debts, Deficits, and Economic Performance. Northampton, MA: Edward Elgar. 
Hanes, Christopher. 1996. "Changes in the Cyclical Behavior of Wages, 1870-1990." Journal of Economic History 56(4): 837-861.

Hein, Eckhard. 2008. Money, Distribution Conflict and Capital Accumulation: Contributions to 'Monetary Analysis.' New York: Palgrave Macmillan.

Hein, Eckhard, and Lena Vogel. 2008. "Distribution and Growth Reconsidered: Empirical Results for Six OECD Countries. Cambridge Journal Economics 32(3): 479-511.

- 2009. "Distribution and Growth in France and Germany: Single Equation Estimations and Model Simulations Based on the Bhaduri/Marglin Model." Review of Political Economy 21(2): 245-272.

Hein, Eckhard, Marc Lavoie, and Till van Treeck. 2012. "Harrodian Instability and the 'Normal Rate' of Capacity Utilization in Kaleckian Models of Distribution and Growth-A Survey." Metroeconomica 63(1): 139-169.

Jacobson, Margaret and Filippo Occhino. 2012. "Behind the Decline in Labor's Share of Income." Economic Trends, February 3. www.clevelandfed.org/research/trends/2012/0212/01 gropro.cfm

Kaldor, Nicholas. 1940. "A Model of the Trade Cycle.” The Economic Journal 50(197): 78-92.

Kalecki, Michal. (1943) 1990. "The Political Economy of Full Employment.” In Jerzy Osiatyński (ed.), Collected Works of Michal Kalecki, Vol. I. Translated by Chester Adam Kisiel. New York: Clarendon Press.

—_. (1943) 1991. Studies in Economic Dynamics. In Jerzy Osiatyński (ed.), Collected Works of Michal Kalecki, Vol. II. Translated by Chester Adam Kisiel. New York: Clarendon Press.

Kenyon, Peter. 1979. “Pricing.” In Alfred S. Eichner (ed.), A Guide to Post-Keynesian Economics. Armonk, NY: M. E. Sharpe.

Keynes, John Maynard. 1937. “The General Theory of Employment.” Quarterly Journal of Economics 51(1): 209-223.

Laramie, Anthony J., and Douglas Mair. 1996. "Taxation and Kalecki's Theory of the Business Cycle.” Cambridge Journal of Economics 20(4): 451-464.

- 2001. "Taxation and Economic Growth: Kalecki's Contribution." Paper presented at "Old and New Growth Theories: An Assessment," Pisa, Italy, October 5-7. 
Lavoie, Marc. 1995. "The Kaleckian Model of Growth and Distribution and its Neo-Ricardian and Neo-Marxian Critiques." Cambridge Journal of Economics 19(6): 789-818.

—. 2000. "Government Deficits in Simple Kaleckian Models.” In Hassan Bougrine (ed.), The Economics of Public Spending: Debts, Deficits, and Economic Performance. Northampton, MA: Edward Elgar.

Lavoie, Marc, Gabriel Rodríguez, and Mario Seccareccia. 2004. "Similitudes and Discrepancies in Post-Keynesian and Marxist Theories of Investment: A Theoretical and Empirical Investigation.” International Review of Applied Economics 18(2): 127-149.

Minsky, Hyman P. (1986) 2008. Stabilizing an Unstable Economy. New York: McGraw Hill.

Moore, Basil. 1988. Horizontalists and Verticalists: The Macroeconomics of Credit Money. New York: Cambridge University Press.

Naastepad, C. W. M., and Servaas Storm. 2006-07. "OECD Demand Regimes (1960-2000)." Journal of Post Keynesian Economics 29(2): 211-246.

Nikiforos, Michalis, and Duncan K. Foley. 2012. "Distribution and Capacity Utilization: Conceptual Issues and Empirical Evidence.” Metroeconomica 63(1): 200-229.

Paladini, Ruggero. 1989. “Kalecki and Fiscal Policy.” In Mario Sabastiani (ed.), Kalecki’s Relevance Today. New York: St. Martin's Press.

Palley, Thomas I. 1998. "Macroeconomics with Conflict and Income Distribution." Review of Political Economy 10(3): 329-342.

- 2002. "Economic Contradictions Coming Home to Roost? Does the U.S. Economy Face a Long-term Aggregate Demand Generation Problem?" Journal of Post Keynesian Economics 25(1): 9-32.

Phillips, A. W. 1954. "Stabilization Policy in a Closed Economy." The Economic Journal 64, Issue 254: 590-323.

Piore, Michael J. 1979. "Pricing Rules.” In Michael J. Piore (ed.), Unemployment and Inflation: Institutionalist and Structuralist Views. Armonk, NY: M. E. Sharpe.

Reich, Robert B. 2010. Aftershock: The Next Economy and America's Future. New York: Alfred A. Knopf.

Robinson, Joan. (1952) 1979. "The Generalisation of the General Theory.” In The Generalisation of the General Theory and Other Essays. New York: St. Martin's Press: $1-76$. 
-1981. "Time in Economic Theory." In What Are the Questions? and Other Essays: Further Contributions to Modern Economics. Armonk, NY: M. E. Sharpe: 86-95.

Sawyer, Malcolm. 1995. Unemployment, Imperfect Competition, and Macroeconomics. Northampton, MA: Edward Elgar.

Shackle, G. L. S. (1972) 1992. Epistemics and Economics: A Critique of Economic Doctrines. Reprint. New Brunswick, NJ: Transaction Publishers.

- 1974. Keynesian Kaleidics: The Evolution of a General Political Economy. Chicago: Aldine Publishing.

Skott, Peter. 1989. Conflict and Effective Demand in Economic Growth. New York: Cambridge University Press.

Steindl, Josef. (1952) 1976. Maturity and Stagnation in American Capitalism. With a new introduction by the author. New York: Monthly Review.

Stockhammer, Englebert, Özlem Onaran, and Stefan Ederer. 2009. "Functional Income Distribution and Aggregate Demand in the Euro Area." Cambridge Journal of Economics 33(1): 139-159.

Tavani, Daniele, Peter Flaschel, and Lance Taylor. 2011. "Estimated Nonlinearities and Multiple Equilibria in a Model of Distributive-Demand Cycles." International Review of Applied Economics 25(5): 519-538.

Tcherneva, Pavlina R. 2006. "Chartalism and the Tax-driven Approach to Money." In Philip Arestis and Malcolm Sawyer (eds.), A Handbook of Alternative Monetary Economics. Northampton, MA: Edward Elgar.

- 2012. "Inflationary and Distributional Effects of Alternative Fiscal Policies: An Augmented Minskyan-Kaleckian Model.” Working Paper No. 706. Annandale-onHudson, NY: Levy Economics Institute of Bard College.

Tobin, James. 1980. Asset Accumulation and Economic Activity: Reflections on Contemporary Economic Activity. Chicago: University of Chicago Press.

Turnovsky, S. J. 2011. "Stabilization Theory and Policy: 50 Years after the Phillips Curve." Economica 78: issue 309: 67-88.

Tymoigne, Éric. 2012. "Measuring Macroprudential Risk through Financial Fragility: A Minskyan Approach.” Working Paper No. 716. Annandale-on-Hudson, NY: Levy Economics Institute of Bard College. 
Veblen, Torstein. (1904) 1975. The Theory of Business Enterprise. Reprint edition. Clifton, NJ: A. M. Kelley.

Wiggins, Stephen. 2003. Introduction to Applied Nonlinear Dynamic Systems and Chaos. Second Edition. New York: Springer.

Wolfson, Martin H. 1994. Financial Crises: Understanding the Postwar U.S. Experience. 2nd Edition. Armonk, NY: M. E. Sharpe.

Wolfstetter, Elmar. 1982. "Fiscal Policy and the Classical Growth Cycle." Journal of Economics 42(4): 375-93.

Wray, L. Randall. 2004. Credit and State Theories of Money: The Contributions of A. Mitchell Innes. Northampton, MA: Edward Elgar.

You, Jong-Il, and Amitava Dutt. 1996. "Government Debt, Income Distribution, and Growth." Cambridge Journal of Economics 20(3): 335-351. 
Table 1. Transactions and changes in stocks and labor force in 5D model

\begin{tabular}{|c|c|c|c|}
\hline & \multicolumn{3}{|c|}{ Sectors: } \\
\hline & $\begin{array}{l}\text { K sector (firms and wealthy } \\
\text { households) }\end{array}$ & $\begin{array}{l}\text { worker } \\
\text { households }\end{array}$ & $\begin{array}{l}\text { P sector } \\
\text { (government) }\end{array}$ \\
\hline \multicolumn{4}{|c|}{ transactions (normalized by capital stock K): } \\
\hline interest & $+\mathrm{ib}$ & n.a. & $-\mathrm{ib}$ \\
\hline distributed profits & $-(1-r) \pi$ & n.a. & $(1-r) \pi$ \\
\hline retained profits & 0 & n.a. & n.a. \\
\hline taxes & $-\tau(\mathrm{ib}+\mathrm{r} \pi)$ & $-\tau\left(\omega_{1} l u+\omega_{2} p\right)$ & $\begin{array}{c}\tau\left(\omega_{1} l u+\omega_{2} p+i b\right. \\
+r \pi)\end{array}$ \\
\hline $\begin{array}{l}\text { unemployment insurance } \\
\text { benefits }\end{array}$ & n.a. & $+\mathrm{uc}$ & $-\mathrm{uc}$ \\
\hline wages & $-\omega_{1} l u$ & $\omega_{1} l u+\omega_{2} p$ & $-\omega_{2} p$ \\
\hline investment goods & $-\delta$ & n.a. & n.a. \\
\hline consumption goods & $-\mathrm{Cw}$ & $+\mathrm{c}_{\mathrm{w}}$ & n.a. \\
\hline total goods & $\begin{array}{c}\mathrm{c}_{\mathrm{w}}-\delta-\text { wastage, inventory } \\
\text { changes, etc. }^{\mathrm{a}}\end{array}$ & $+\mathrm{c}_{\mathrm{w}}$ & n.a. \\
\hline public services & \multicolumn{2}{|l|}{$\mathrm{p}$} & $-\mathrm{p}$ \\
\hline labor services ${ }^{b}$ & lu & $-(1 \mathrm{u}+\mathrm{p})$ & $\mathrm{p}$ \\
\hline \multicolumn{4}{|c|}{ changes in stocks (normalized by capital stock K): } \\
\hline capital goods & g & n.a. & n.a. \\
\hline government bonds $(\dot{b})$ & 0 & n.a. & 0 \\
\hline money $(\dot{\mathcal{M}})$ & $d f$ & n.a. & $-d f$ \\
\hline \multicolumn{4}{|c|}{ changes in size of labor force: } \\
\hline $\begin{array}{l}\text { K-sector labor force } / \mathrm{k} \\
\text { (lf })\end{array}$ & n.a. & $l f\left(g_{0}-g\right)$ & n.a. \\
\hline $\begin{array}{l}\text { P-sector labor force } / \mathrm{k} \\
(p \dot{l} f)\end{array}$ & n.a. & $p l f\left(g_{0}-g\right)$ & n.a. \\
\hline
\end{tabular}

Notes: ${ }^{a}$ The inclusion of this term is necessary because the goods-market equilibrium condition (19) does not hold at all times in the dynamic models in this paper. See the discussion below equation (21) in section 3 . $^{\mathrm{b}}$ Amounts of labor normalized so that 1 unit of labor services is needed to produce 1 unit of public services. See section 2. 
Figure 1. $\mathrm{f}_{3}$ Function in Kaldorian Investment Model

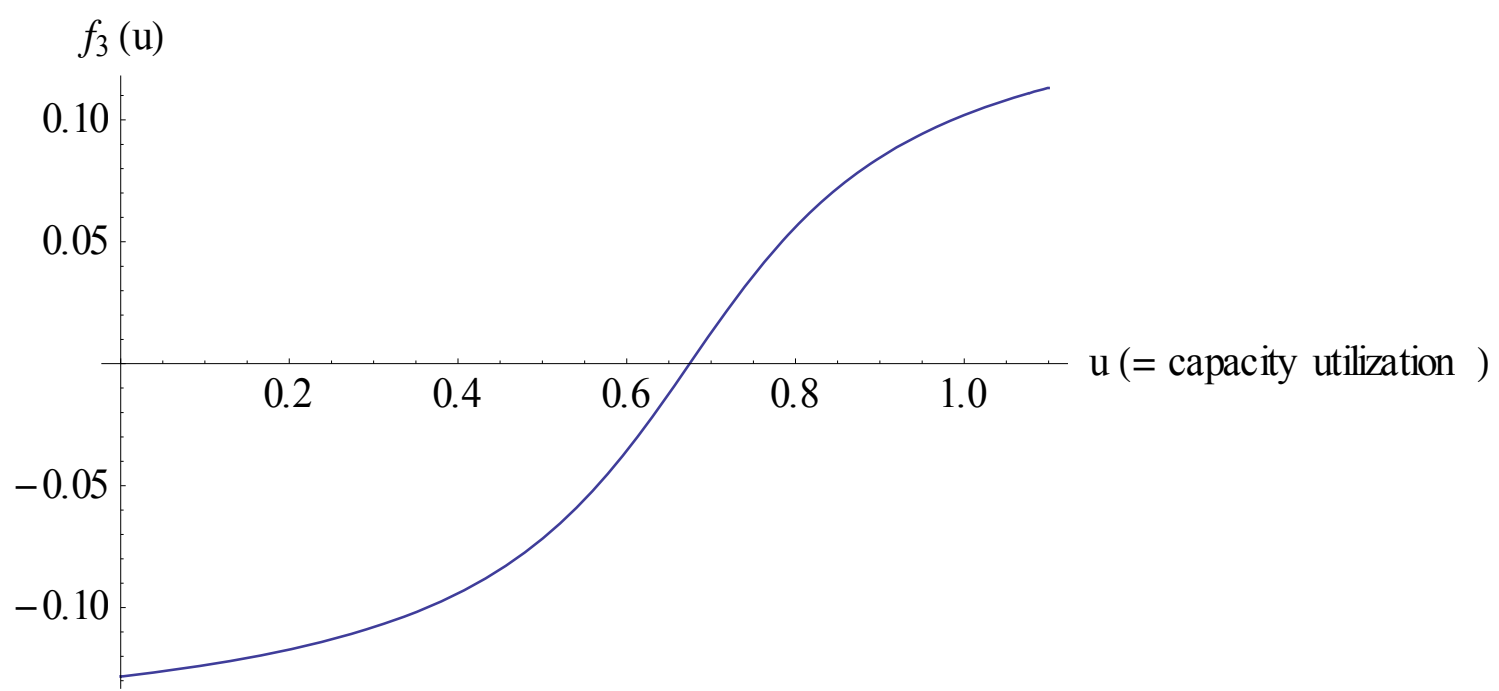

Figure 2. Schematic Diagram of Nonlinear Fiscal Multiplier Relationship $\mathrm{u}(=$ capacity utilizaton $)$

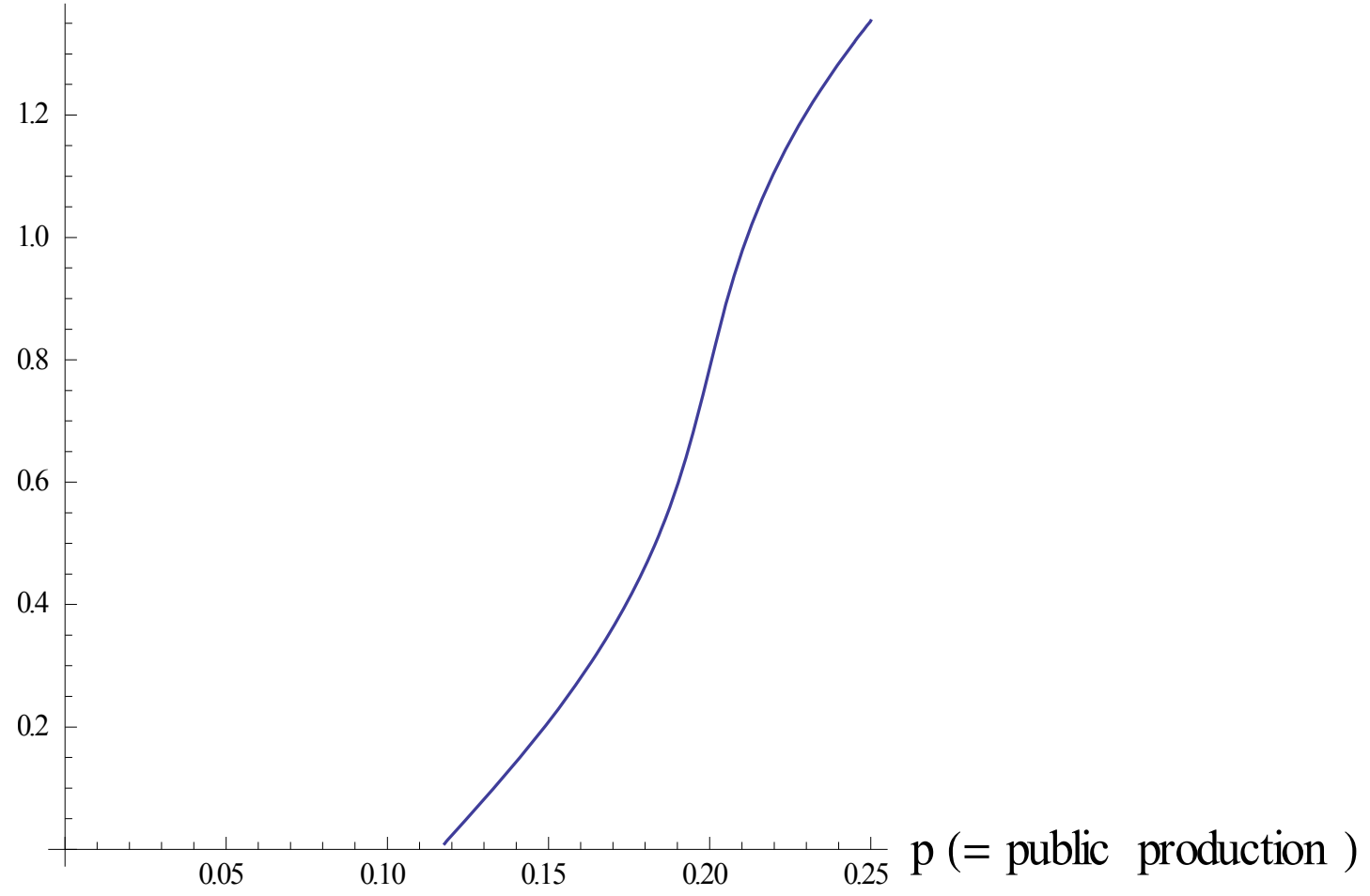


Figure 3. Vector-Field Depiction of 2D Dynamic System with Capacity-Utilization/PublicSector-Production Policy Targeting Rule

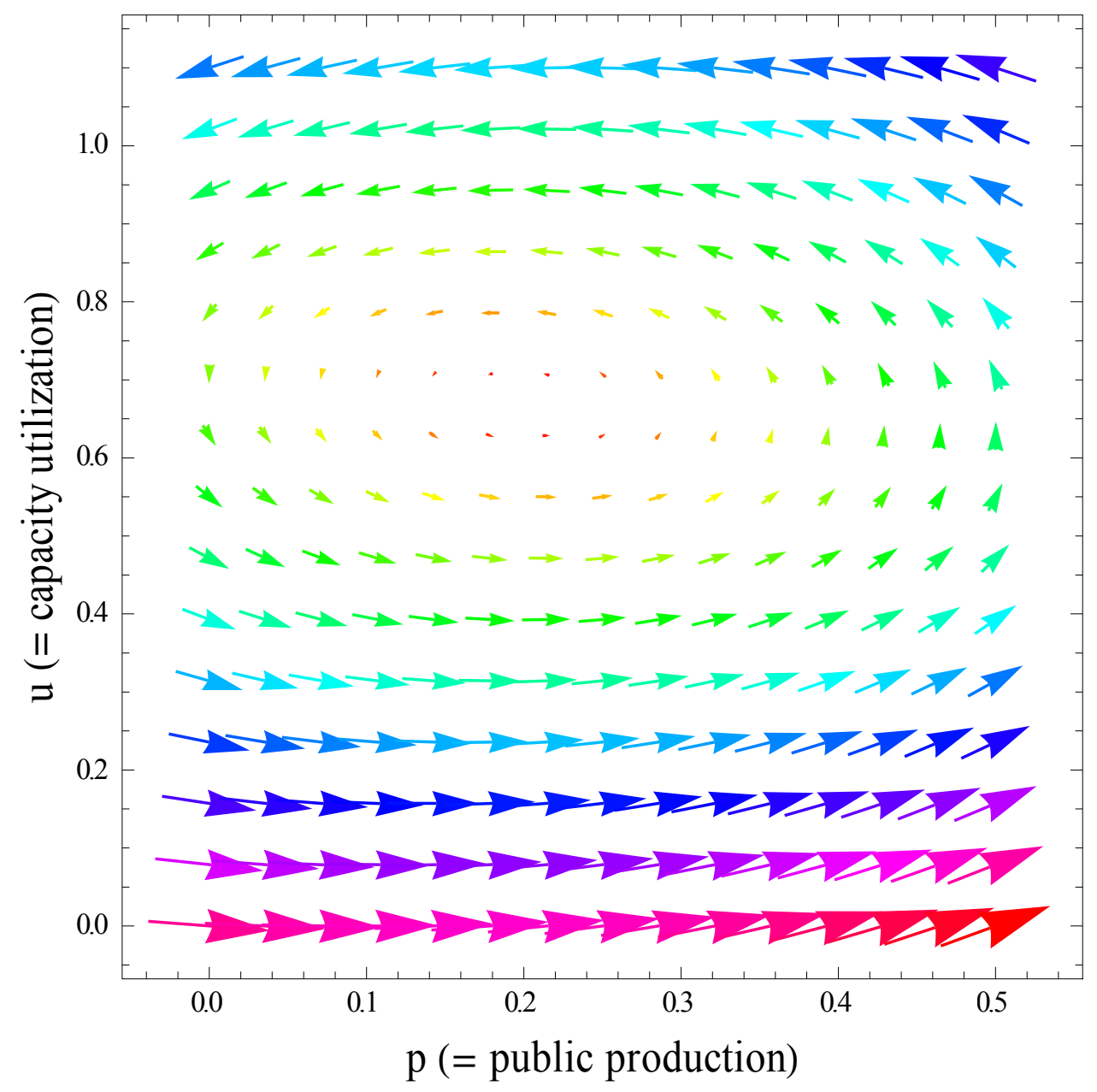


Figure 4. Flowline Depiction of 2D Dynamic System with Capacity-Utilization/Public-SectorProduction Policy Targeting Rule

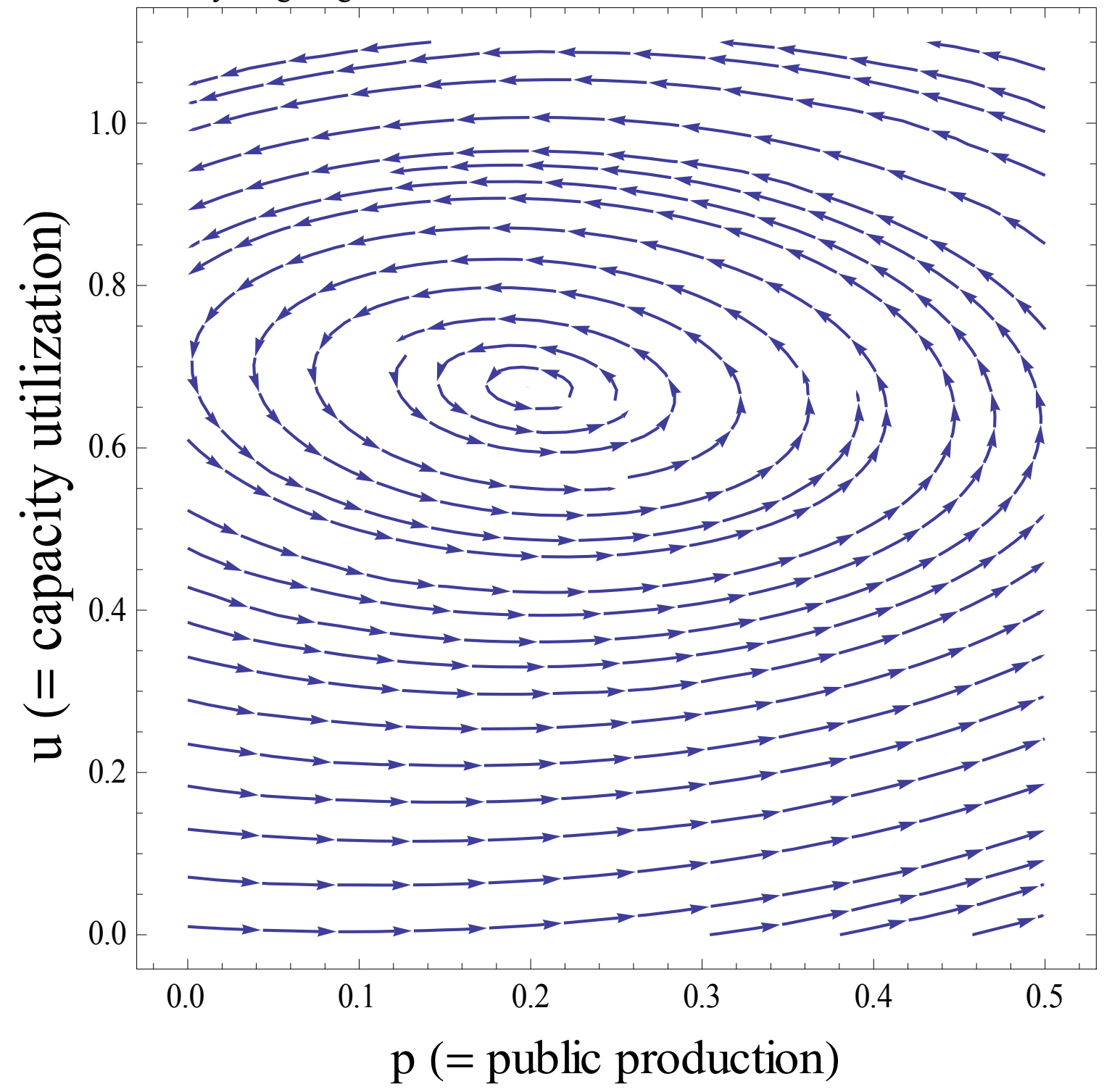


Figure 5. Example Pathway of 2D Dynamic System with Capacity-Utilization/Public-SectorProduction Targeting Policy Rule $\mathrm{u}(=$ capacity utilization $)$

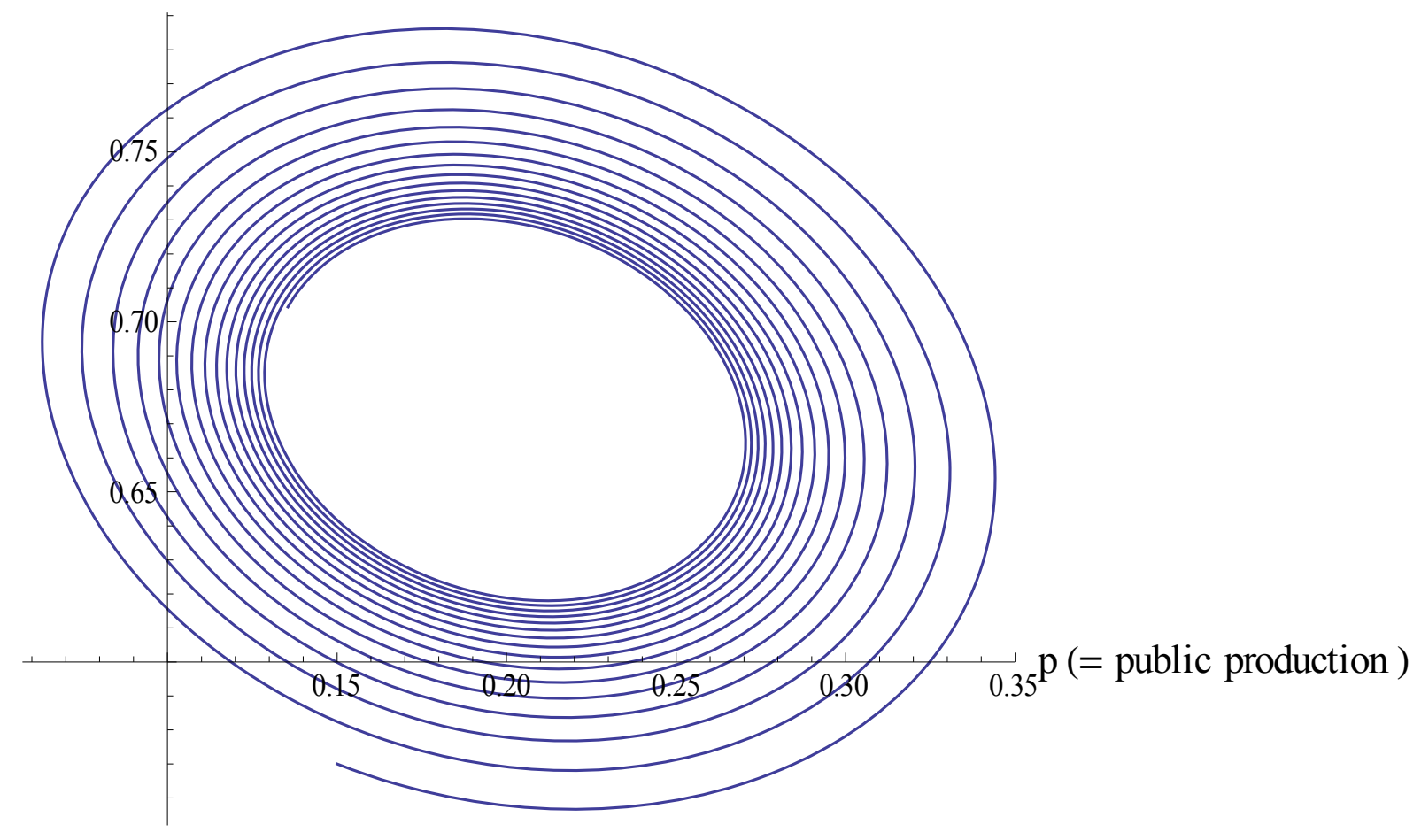


Figure 6. Dysfunctional Finance: Flowline Depiction of Same System with Balanced-Budget Targeting Policy Rule

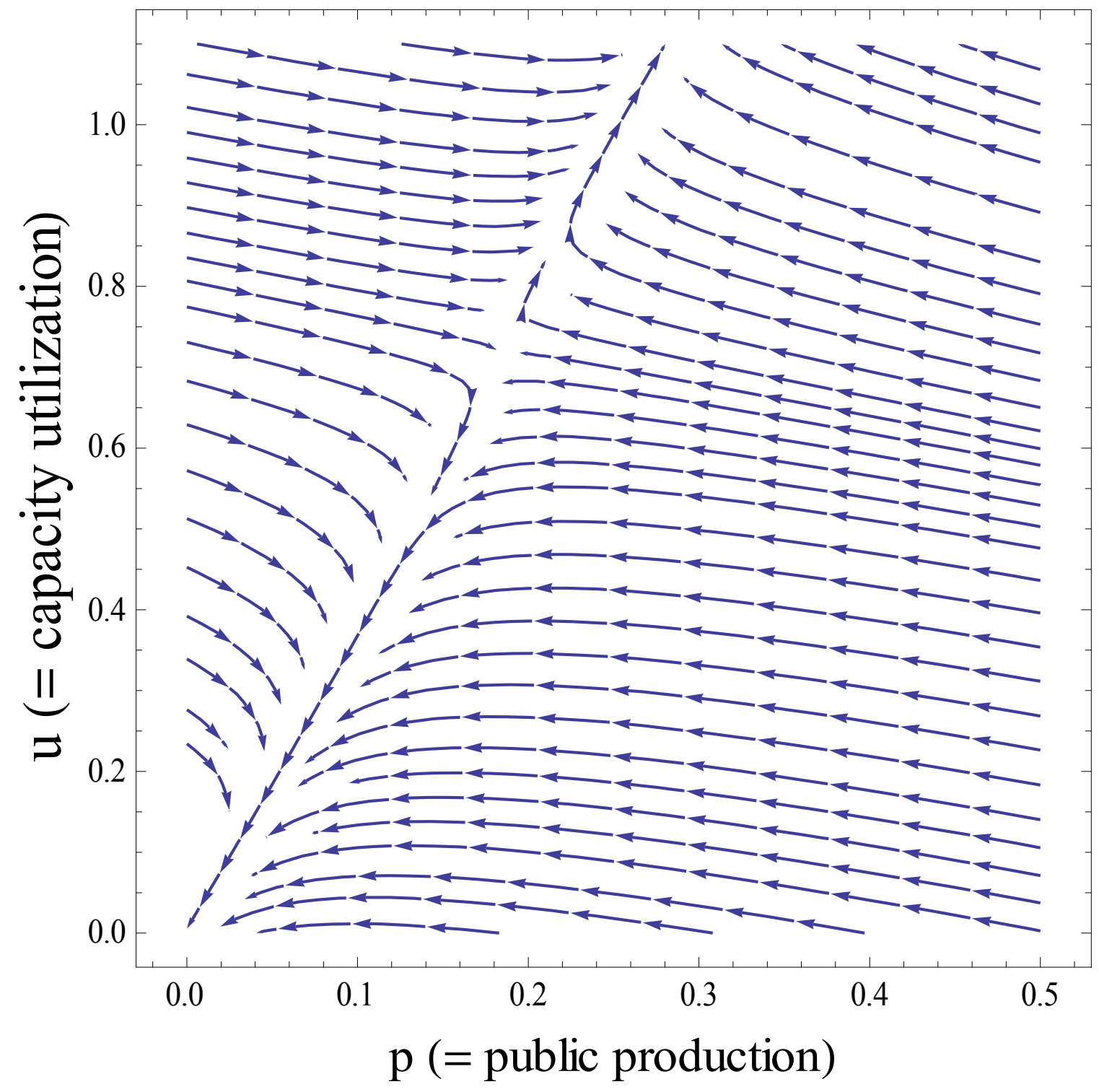


Figure 7. Kaleckian Component of Markup-Dynamics Model

Rate of Change of Markup-Pricing Ratio

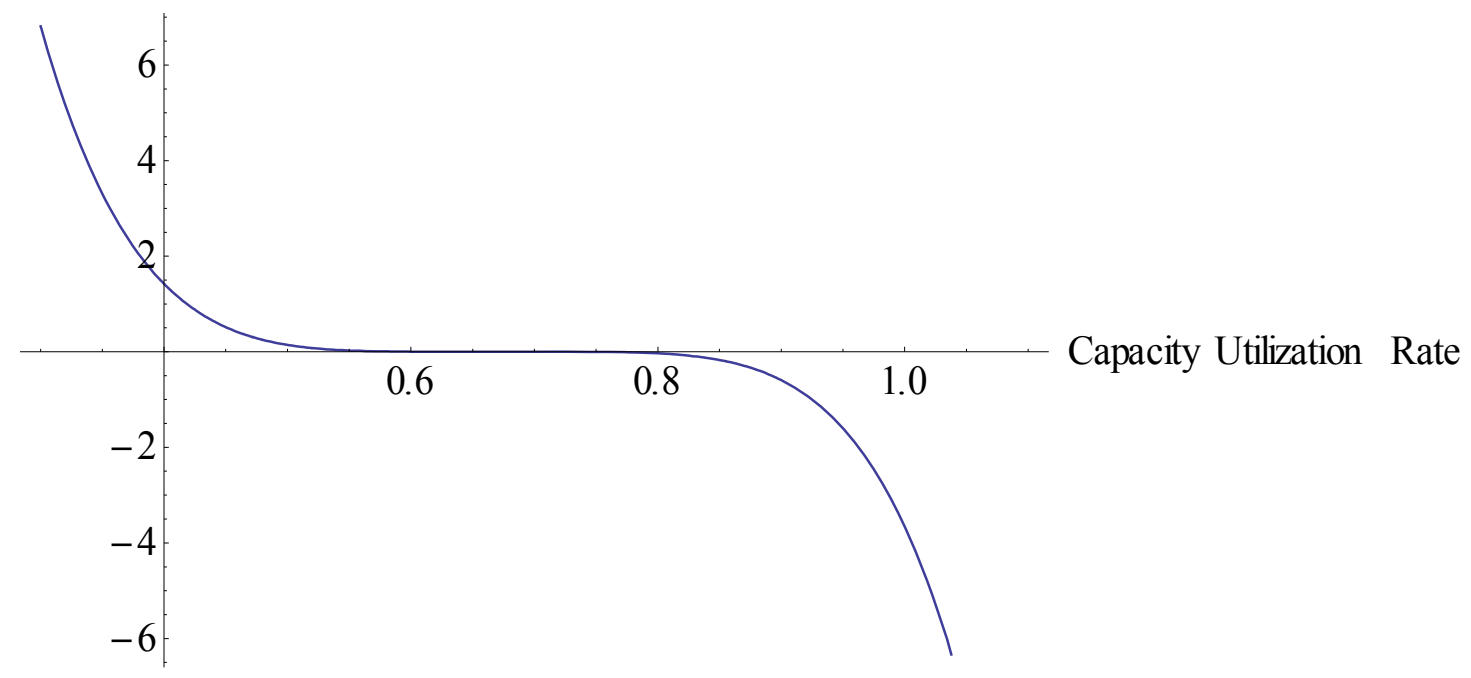

Figure 8. Goodwinian Component of Markup-Dynamics Model

rate of change of markup -pricing ratio

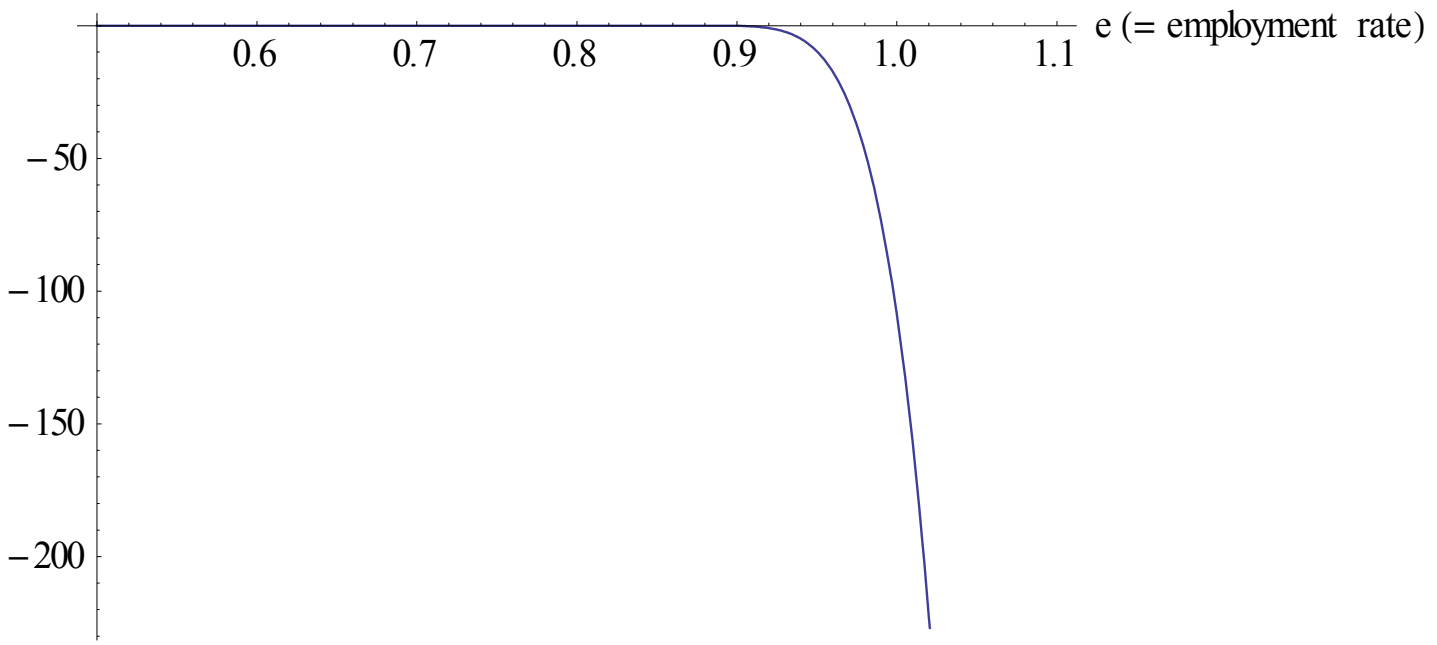


Figure 9a. Example of Pathway in 3D System with Kaleckian Markup Dynamics and Small Adjustment Parameter: p-u-m Space

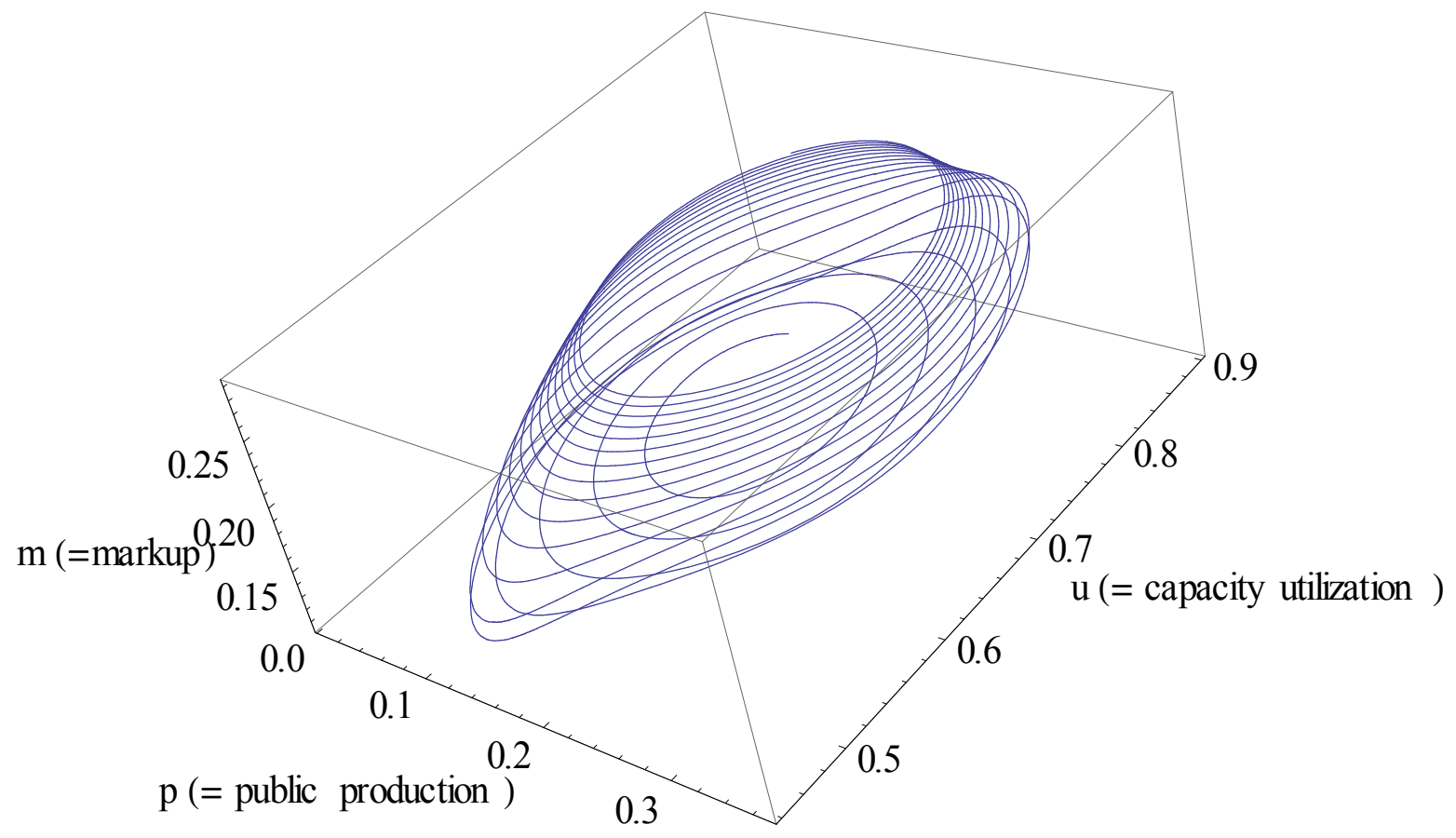

Figure 9b. Same Example: e- $\mathcal{M}$-df Space

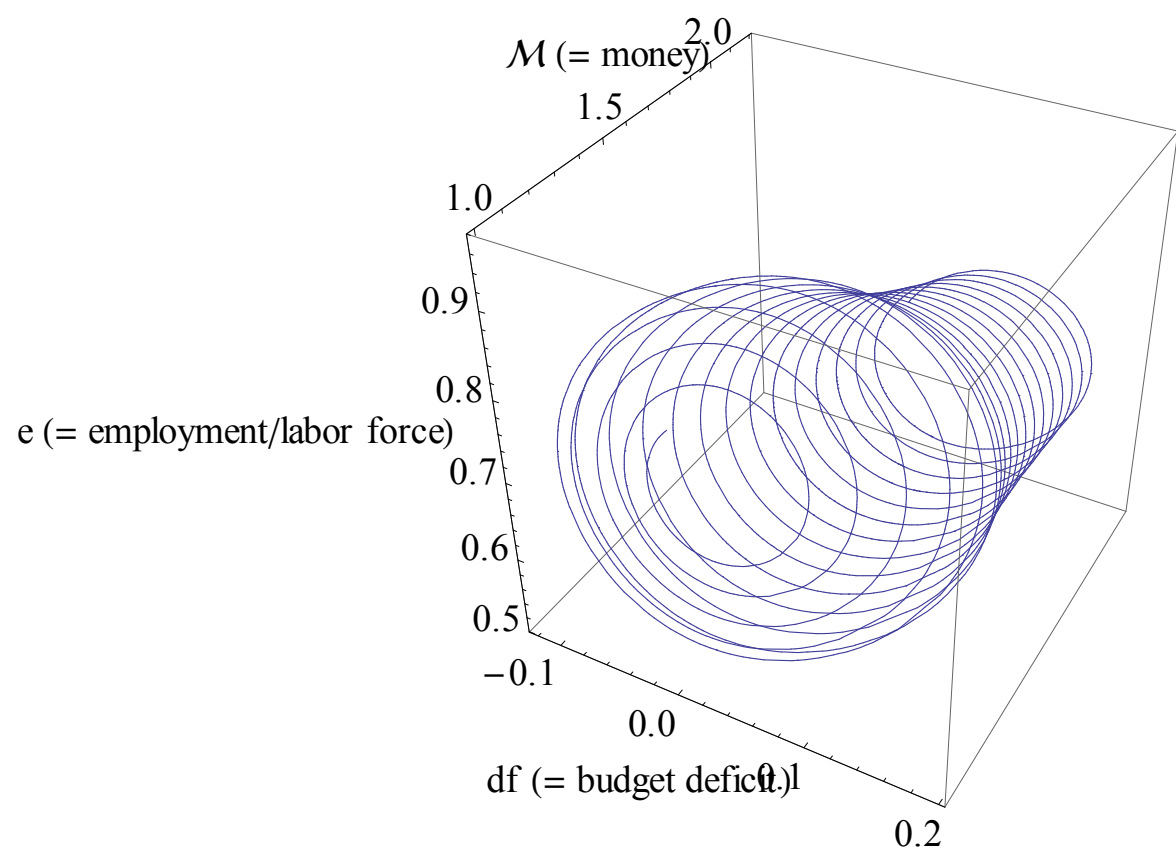


Figure 10a. Example of Pathway in 3D System with Kaleckian Markup Dynamics and Large Adjustment Parameter: p-u-m Space

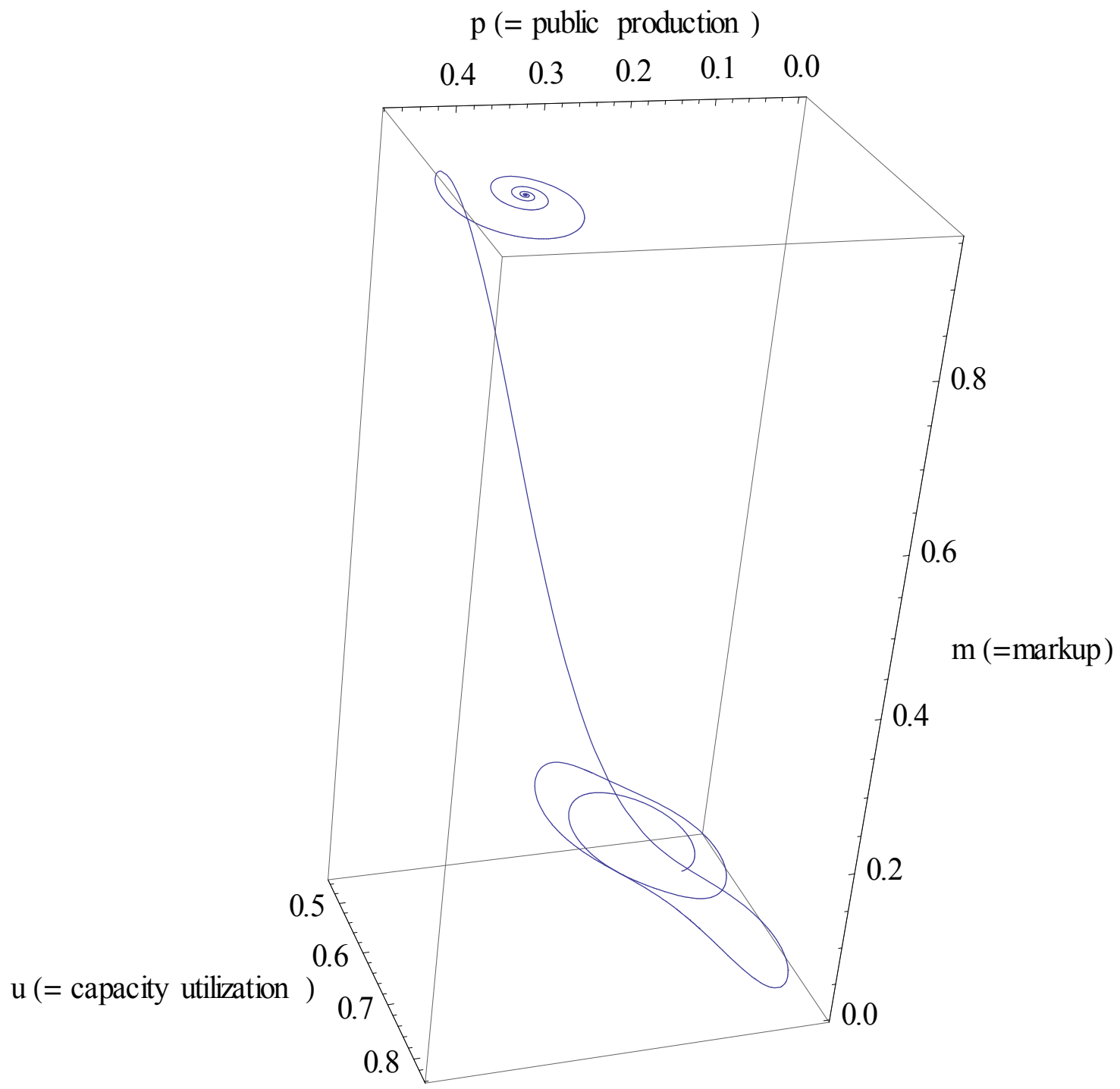


Figure 10b. Same Example: e- $\mathcal{M}$-df Space

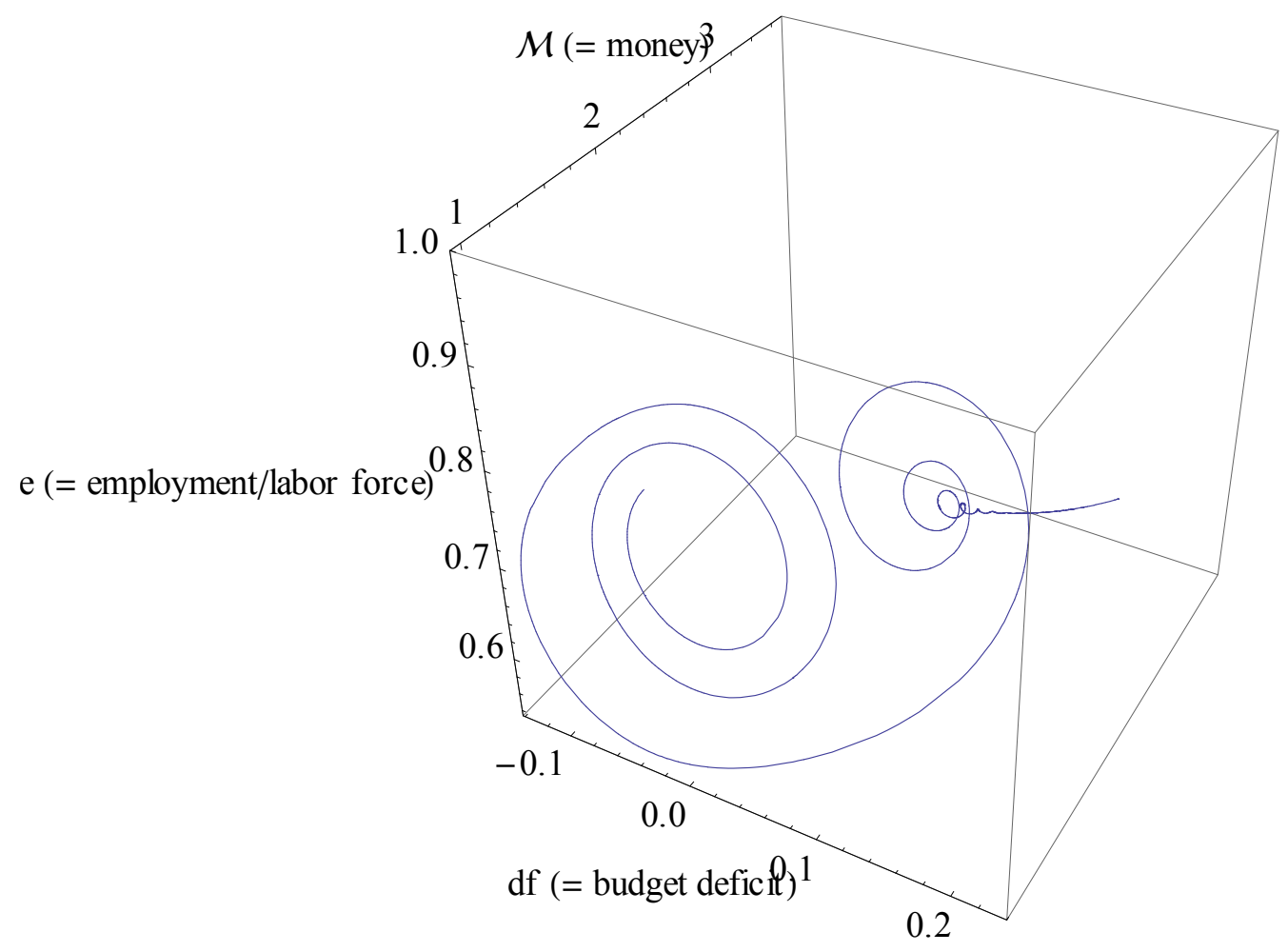


Figure 11a . Example of Pathway in 5D System with Goodwinian ("Radical") Pricing Model: pu-m Space

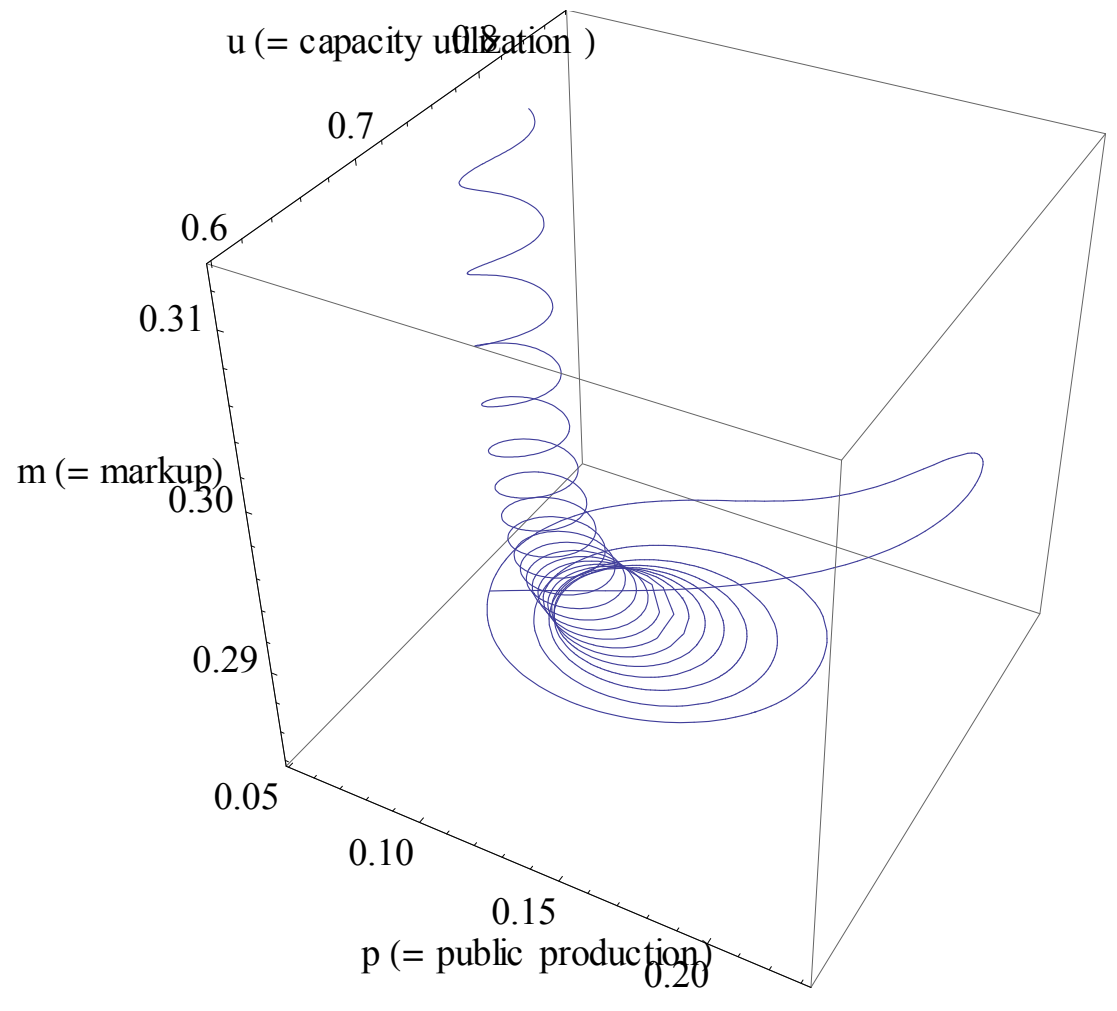


Figure $11 b$. Same Example: e- $\mathcal{M}$-df Space

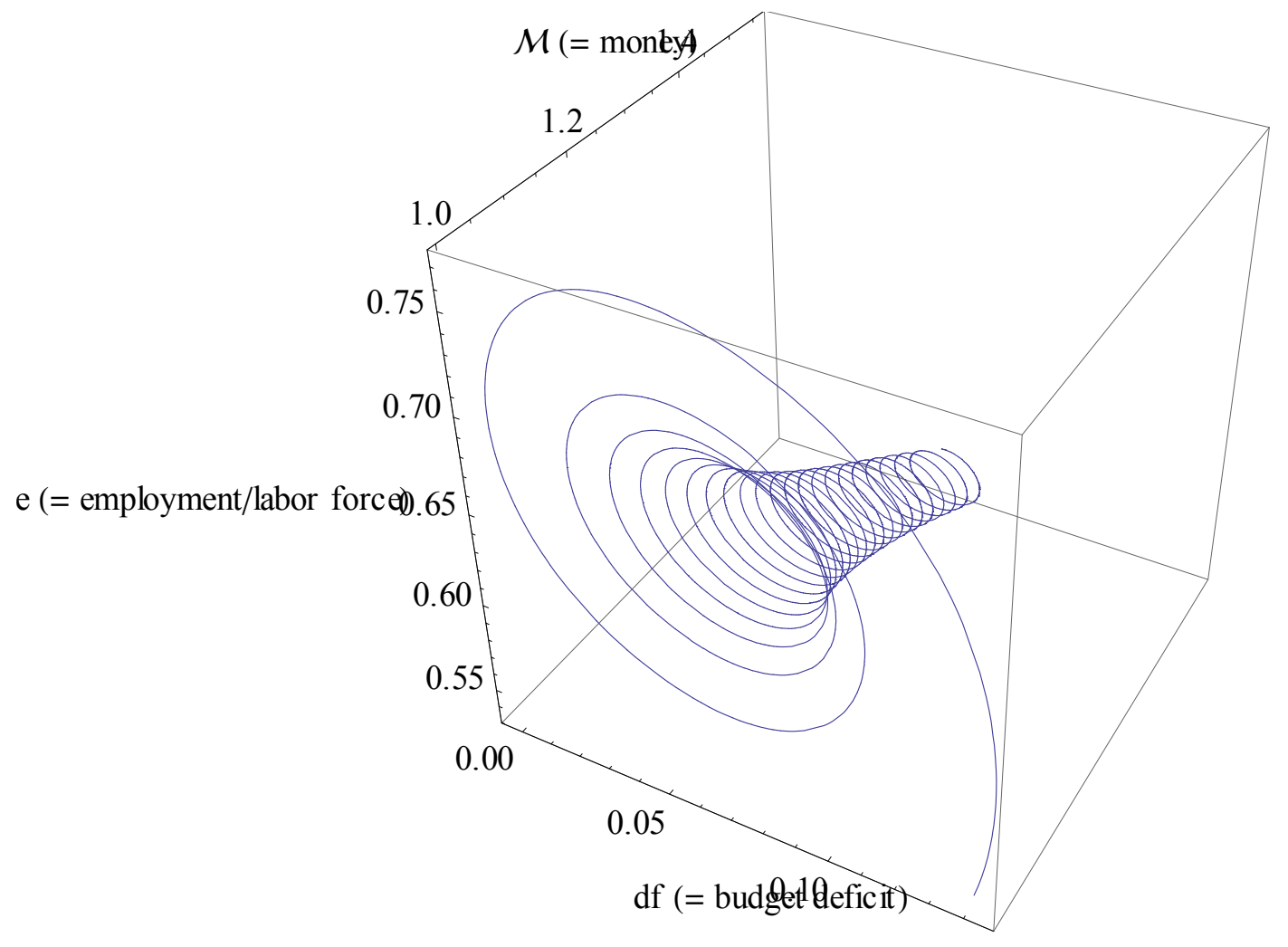


Figure 12a. Example of Pathway in 5D System with "Post-Keynesian" Pricing Model: p-u-m Space

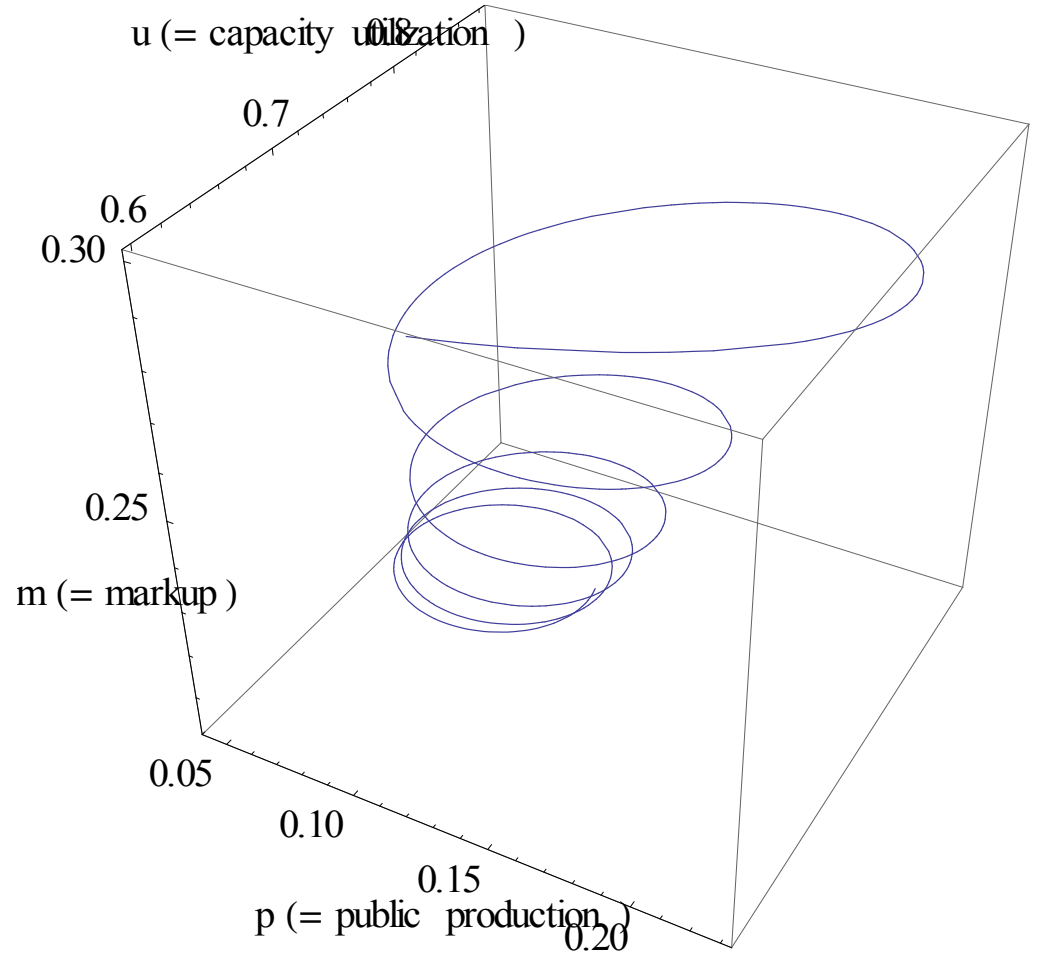


Figure $12 b$. Same Example: e- $\mathcal{M}$-df Space

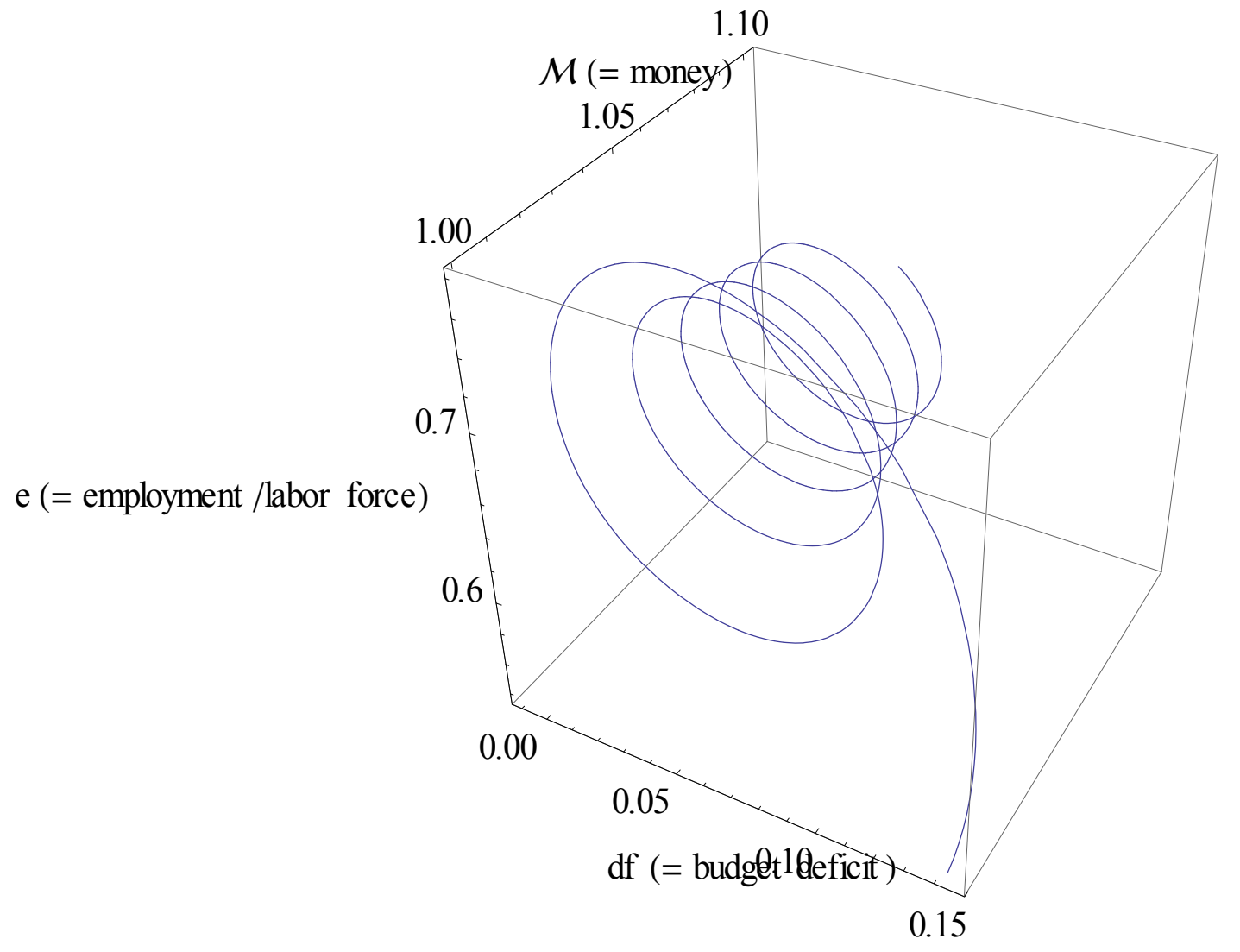


Figure 13a. Example of Pathway in 5D System with Slow, Irregular Motion: p-u-m Space

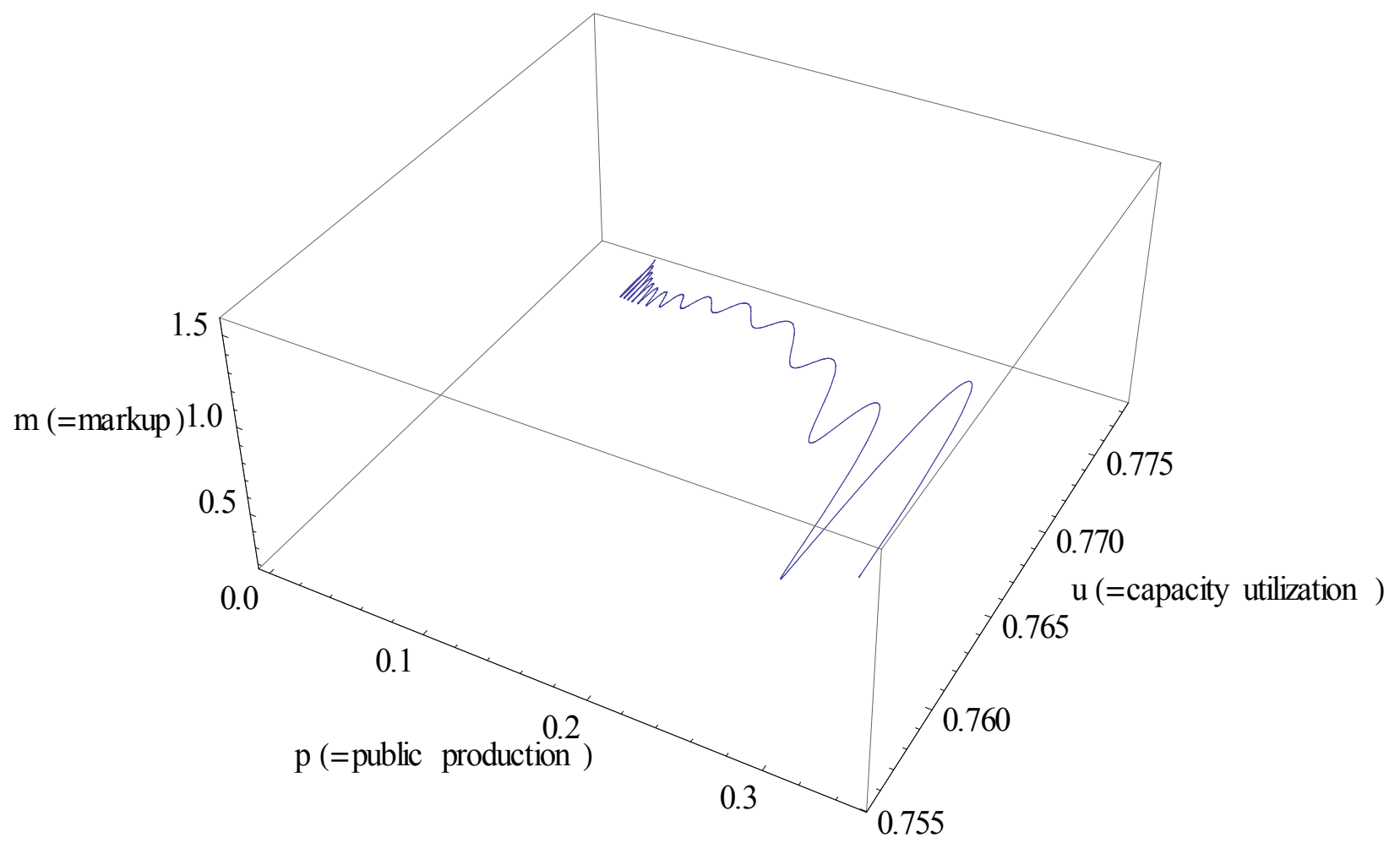


Figure 13b. Same Example: e- $\mathcal{M}$-df Space

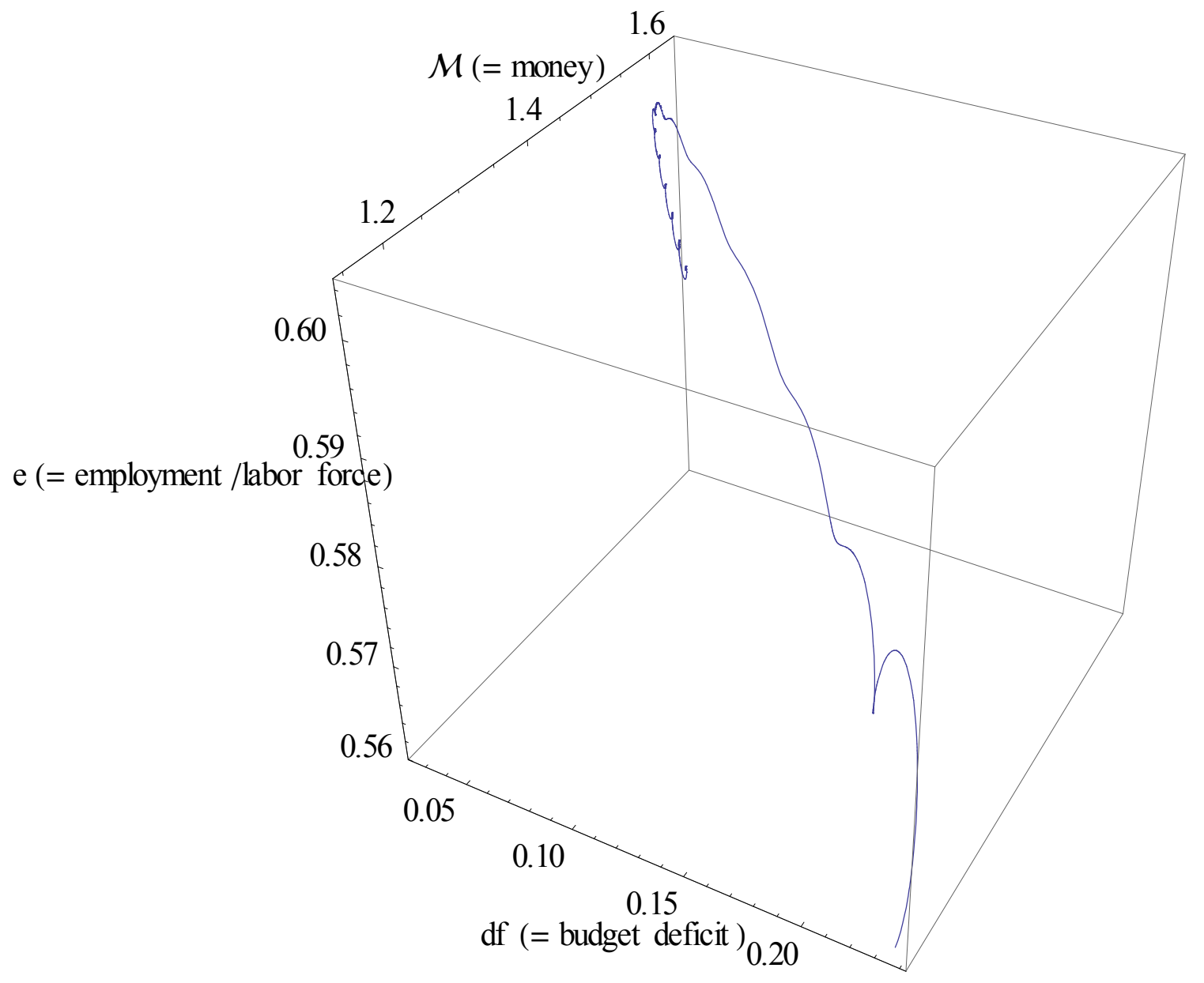




\section{APPENDIX: PARAMETER VALUES AND FUNCTIONAL FORMS USED IN THE COMPUTABLE EXAMPLES}

As noted in the Introduction, the parameter values used for the simulations discussed in sections

3, 5, and 6 are somewhat arbitrary. However, some may find a list of these values to be helpful. This appendix lists their values as well as the initial conditions and the functional forms used in the net-investment-demand and markup-dynamics equations.

\section{D Nonlinear Model (sections 3 and 4):}

$$
\begin{aligned}
& \text { auton }=.04 \\
& \alpha_{1}=10 \\
& \alpha_{2}=.6 \\
& \alpha_{3}=6.3 \\
& \alpha_{4}=5 \\
& \beta(\bar{\imath})=.15 \\
& \delta=.01 \\
& \gamma=5 \\
& \kappa=.05 \\
& \mu=.65 \\
& \varphi=.1 \\
& \tau=.2 \\
& \chi=1 \\
& \omega_{1}=\omega_{2}=1 \\
& \mathrm{a}_{1}=\mathrm{a}_{2}=1 \\
& \bar{\imath}=.1 \\
& 1=1
\end{aligned}
$$


$\mathrm{p}_{\mathrm{T}}=.2$

$\mathrm{r}=.85$

$\mathrm{u}_{\mathrm{T}}=0.6744941493372616$

$\mathrm{f}_{3}(\mathrm{u})=\varphi^{*} \arctan \left[\gamma^{*}\left(\mathrm{u}-\mathrm{u}_{\mathrm{T}}\right)\right]$

Full model with Kaleckian markup-dynamics model and no unemployment insurance system (See sections 5 and 6 and figures 9a, 9b, 10a, and 10b):

(Unless listed here, parameter values and functional forms are the same as above.)

$\mathrm{f}_{8}(\mathrm{u})=\left(\alpha_{9} *\left(\mathrm{u}^{\mathrm{eq}}-\mathrm{u}\right)\right)^{5}$

$\alpha_{2}=.6 ; \alpha_{3}=4.2 ; \alpha_{4}=10.4 ; \alpha_{5}=1 ; \alpha_{8}=30$ (in figure 9a and $b$ ) OR 200 (in figure 10a and $b$ ); $\alpha_{9}=$ $2 ; \gamma=4.5 ; \varphi=.1 ; \mathrm{u}_{\mathrm{T}}=0.6744941493372614 ; \alpha_{6}=\alpha_{7}=\alpha_{10}=\alpha_{11}=\alpha_{12}=0$

\section{Initial Conditions:}

$p[0]=.16 ; u[0]=.75 ; m[0]=.165 ; \mathcal{M}[0]=1$

Full model with unemployment insurance system (See sections 5 and 6 and figures 11a, 11b, 12a, 12b, 13a, and 13b):

(Unless listed here, parameter values are the same as above.)

$\alpha_{2}=1 ; \alpha_{3}=10 ; \alpha_{4}=40$

Example shown in figures 11a and b: $\alpha_{5}=.5 ; \alpha_{6}=\alpha_{7}=\alpha_{8}=\alpha_{9}=\alpha_{10}=0 ; \alpha_{11}=1500 ; \alpha_{12}=5$

Example shown in figures 12a and $b: \alpha_{5}=.6 ; \alpha_{6}=-75 ; \alpha_{7}=1 ; \alpha_{8}=2 ; \alpha_{9}=2 ; \alpha_{10}=4 ; \alpha_{11}=\alpha_{12}=$ 0

Example shown in figures 13a and b: $\alpha_{5}=.6 ; \alpha_{6}=1 ; \alpha_{7}=1 ; \alpha_{8}=2 ; \alpha_{9}=10 ; \alpha_{10}=4 ; \alpha_{11}=\alpha_{12}=$ 0

$\tilde{\mathrm{e}}=\left(\mathrm{p}_{\mathrm{T}}+\mathrm{u}^{\mathrm{eq}}\right) / 1.1=0.790735$

$\gamma=6.7$ 
$\varphi=.1$

$\rho=.35$

$\tau=.22$

$\mathrm{g}_{\text {normal }}=\mathrm{g}_{0}=.01$

$\mathrm{p}_{\mathrm{T}}=.1$

$\mathrm{u}_{\mathrm{T}}=0.7698086523314395$

wagenorm $=5 / 6$

$\pi_{\text {target }}=\mathrm{u}^{\mathrm{eq} *}(1 / 6)$

$\mathrm{f}_{7}=\left(\left(\mathrm{g}_{0}-\mathrm{g}_{\mathrm{d}}\right)^{3}-\mathrm{Abs}\left[\left(\mathrm{g}_{0}-\mathrm{g}_{\mathrm{d}}\right)^{3}\right]\right) / 2$

$\mathrm{f}_{9}=\left((-1) \mathrm{a}_{12}(\mathrm{e}-\tilde{\mathrm{e}})^{5}-\operatorname{Abs}\left[\left((-1) \mathrm{a}_{12}\left(\mathrm{e}^{5}-\tilde{\mathrm{e}}\right)\right)\right]\right) / 2$

Initial conditions:

figures $11 \mathrm{a}$ and $\mathrm{b}$ :

$p[0]=.13 ; u[0]=.603 ; m[0]=.3 ; l f[0]=1.1 ;$ no separate plf variable; $\mathcal{M}[0]=1$

figures $12 \mathrm{a}$ and $\mathrm{b}$ :

$p[0]=.13 ; u[0]=.6 ; m[0]=.3 ; l f[0]=1.1 ;$ no separate plf variable; $\mathcal{M}[0]=1$

figures $13 \mathrm{a}$ and $\mathrm{b}$ :

$p[0]=.13 ; u[0]=.603 ; m[0]=.3 ; l f[0]=1.1 ;$ no separate plf variable; $\mathcal{M}[0]=1$ 